Monetary Policy Shocks and Foreign Investment Income: Evidence from a large Bayesian VAR Simone Auer

\author{
SNB Working Papers \\ 2/2014
}




\section{Legal Issues}

\section{DISCLAIMER}

The views expressed in this paper are those of the author(s) and do not necessarily represent those of the Swiss National Bank. Working Papers describe research in progress. Their aim is to elicit comments and to further debate.

\section{COPYRIGHTC}

The Swiss National Bank (SNB) respects all third-party rights, in particular rights relating to works protected by copyright (information or data, wordings and depictions, to the extent that these are of an individual character).

SNB publications containing a reference to a copyright (C) Swiss National Bank/SNB, Zurich/year, or similar) may, under copyright law, only be used (reproduced, used via the internet, etc.) for non-commercial purposes and provided that the source is mentioned. Their use for commercial purposes is only permitted with the prior express consent of the SNB.

General information and data published without reference to a copyright may be used without mentioning the source. To the extent that the information and data clearly derive from outside sources, the users of such information and data are obliged to respect any existing copyrights and to obtain the right of use from the relevant outside source themselves.

\section{LIMITATION OF LIABILITY}

The SNB accepts no responsibility for any information it provides. Under no circumstances will it accept any liability for losses or damage which may result from the use of such information. This limitation of liability applies, in particular, to the topicality, accuracy, validity and availability of the information.

ISSN 1660-7716 (printed version)

ISSN 1660-7724 (online version)

(C) 2014 by Swiss National Bank, Börsenstrasse 15,

P.O. Box, $\mathrm{CH}-8022$ Zurich 


\title{
Monetary Policy Shocks and Foreign Investment Income: Evidence from a large Bayesian VAR*
}

\author{
Simone Auer ${ }^{\dagger}$
}

January 24, 2014

\begin{abstract}
This paper assesses the transmission of monetary policy in a large Bayesian vector autoregression based on the approach proposed by Banbura, Giannone and Reichlin (2010). The paper analyzes the impact of monetary policy shocks in the United States and Canada not only on a range of domestic aggregates, trade flows, and exchange rates, but also foreign investment income. The analysis provides three main results. First, a surprise monetary policy action has a statistically and economically significant impact on both gross and net foreign investment income flows in both countries. Against the background of growing foreign wealth and investment income, this result provides preliminary evidence that foreign balance-sheet channels might play an increasingly important role for monetary transmission. Second, the impact of monetary policy on foreign investment income flows differs considerably across asset categories and over time, suggesting that the investment instruments and the currency denomination of a country's foreign assets and liabilities are potentially relevant for the way in which monetary policy affects the domestic economy. Finally, the results support existing evidence on the effectiveness of large vector autoregressions and the Bayesian shrinkage approach in addressing the curse of dimensionality and eliminating price and exchange rate puzzles.
\end{abstract}

JEL classification: E52, F41, F42, C53

Keywords: monetary policy transmission, foreign investment income, Bayesian VAR

*I would like to thank Domenico Giannone for his help in the empirical implementation, and Cédric Tille, Mathias Hoffmann, Charles Wyplosz, participants at the SNB Brown Bag Seminar, the Buba-OeNB-SNB Workshop 2012 in Vienna, the 2013 EEA-ESEM Annual Meetings in Gothenburg, and an anonymous referee of the SNB Working Paper Series for useful comments. All remaining errors are mine. The views expressed in this paper are those of the author and do not necessarily represent those of the Swiss National Bank.

${ }^{\dagger}$ Swiss National Bank. E-mail: simone.auer@snb.ch. Earlier versions of this paper may have been circulated under my maiden name Simone Meier. 


\section{Introduction}

This paper assesses the transmission of monetary policy in a large Bayesian vector autoregression (BVAR) based on the approach proposed by Banbura, Giannone, and Reichlin (2010, henceforth BGR, 2010). The paper analyzes the impact of monetary policy not only on a range of domestic economic aggregates, trade flows, and exchange rates, but also foreign investment income flows, which is novel in the literature. The analysis of monetary policy's impact on foreign investment income flows allows to offer preliminary evidence on the potential relevance of foreign balance-sheet channels of monetary policy. Monetary policy can affect the domestic currency valuation of foreign wealth and income flows through monetary policy-induced changes in exchange rates, and dividend and interest payments. These monetary policy-induced fluctuations in foreign investment income receipts and payments, in turn, affect firms' and households' cash and income flows, and thus their balance sheets and financial positions. Finally, given asymmetric information in financial markets, these fluctuations in financial positions potentially influence borrowers' credit conditions and thus aggregate investment and consumption spending. ${ }^{1}$

The existing literature on balance-sheet channels of monetary policy is focused on domestic in contrast to foreign cash and income flows. ${ }^{2}$ However, against the background of rapid international financial integration, foreign balance-sheet channels might play an increasingly important role for the transmission of monetary policy. Foreign assets and liabilities constitute an increasing component of firms' and households' overall wealth, and foreign investment income receipts and payments an increasing component of firms' and households' overall cash and income flows. Between 1970 and 2007, the sum of gross foreign assets and liabilities in the United States increased tenfold, from around 27 to over 270 percent of GDP. ${ }^{3}$ Over the same period, the sum of US foreign investment income receipts and payments increased from around 2 to over 10 percent of GDP (see Figure A1 in Appendix A). ${ }^{4}$ The foreign component of firms' and households' cash and income flows might thus become more and more relevant for the way in which monetary policy affects the economy.

\footnotetext{
${ }^{1}$ See Bernanke and Gertler (1995), Bernanke, Gertler, and Gilchrist (1996), and Zurlinden (2005) for a discussion of balance-sheet channels.

${ }^{2}$ See Gertler and Gilchrist (1993, 1994), Bernanke and Blinder (1992), Iacoviello and Minetti (2008), Ciccarelli, Maddaloni and Peydró (2010), Bond et al. (2003), Chatelain et al. (2003), Ashcraft and Campello (2007), Alpanda and Aysun (2012), and Mishkin (1978).

${ }^{3}$ See updated and extended version of the External Wealth of Nations Mark II database developed by Lane and Milesi-Ferretti (2007). Between 1970 and 2007, the average sum of gross foreign assets and liabilities of industrial countries increased from around 60 to 600 percent of GDP.

${ }^{4}$ In Canada, the second country included in the analysis of this paper, the sum of foreign assets and liabilities increased from around 100 percent of GDP in 1982 to over 200 percent of GDP in 2007. Over the same period, the sum of Canada's total foreign investment income receipts and payments fluctuated at around 10 percent of GDP (see Figure A2 in Appendix A).
} 
In order to study monetary policy's impact on a wide range of economic variables, including total and decomposed foreign investment income flows, and to mitigate limited information problems occurring in small-scale vector autoregressions (VARs), this paper estimates a large model, including up to 26 variables. ${ }^{5}$ And in order to handle such a large dynamic model, the paper applies the "Bayesian shrinkage" approach proposed by BGR (2010). This approach is based on a Bayesian estimation procedure with a particular specification of informative priors. A Bayesian estimation with informative priors is now a standard tool in applied macroeconomics. ${ }^{6}$ A particular issue in these approaches is the optimal choice of the informativeness or the tightness of the priors (the "degree of shrinkage"), i.e. the level of confidence that is attached to the econometricians' prior distributional assumptions in relation to the information contained in the data. BGR (2010) propose a particular procedure in which the tightness of the priors is set in relation to the model size, i.e. increased as more variables are added. They show that such a procedure can be successfully applied also in large models and without any further restrictions on the model. The approach effectively addresses overfitting problems and the curse of dimensionality and outperforms small models in both forecast accuracy and structural analysis. It is thus a valid alternative to factor models and global and panel VARs to handle large dynamic systems. In the monetary policy literature this approach is used, e.g., by Beauchemin and Zaman (2011), Carriero, Kapetanios, and Marcellino (2009), and Bloor and Matheson (2009). However, their focus is mainly on forecast evaluations and, in contrast to this paper (with the exception of exchange rates), on domestic variables. ${ }^{7}$

The analysis of this paper is based on a sample of two different countries, the United States and Canada. It provides three main results. First, a surprise monetary policy action has a statistically and economically significant impact on both gross and net foreign investment income flows in both the United States and Canada. While this result does not provide evidence of the independent effect of foreign balance-sheet channels of monetary transmission, it provides preliminary evidence that such channels might be increasingly important for the transmission of monetary policy. Second, the impact of monetary policy on foreign investment income flows differs considerably across asset categories and over time, suggesting that the instruments and the currency denomination of a country's foreign assets and liabilities might potentially be relevant for the way in which monetary policy affects the domestic economy. Finally, a contractionary monetary policy shock induces decreases in aggregate price levels, exchange rate appreciations, and reasonable responses in real and

\footnotetext{
${ }^{5}$ See the literature review for a discussion of small versus large VARs.

${ }^{6}$ See Litterman (1986) or Cicarelli and Rebucci (2003).

${ }^{7}$ Giannone, Lenza, and Reichlin (2008) use the approach in an analysis of the explanation of the Great Moderation.
} 
financial indicators, which supports existing evidence on the effectiveness of large VARs and the Bayesian shrinkage approach in addressing the curse of dimensionality and eliminating price and exchange rate puzzles.

The rest of the paper is structured as follows. Section 2 provides an overview of the related literature, Section 3 presents the methodology and the data. Section 4 discusses the main results and the robustness checks, and the last section concludes.

\section{Related literature}

This paper is related to two strands of the literature: the VAR-based literature on monetary policy transmission, generally, and the (VAR and non-VAR-based) literature on balancesheet channels of monetary policy, more specifically.

VAR-based studies on monetary policy transmission can be distinguished with respect to the strategies for estimating the regression parameters, the strategies for identifying the shocks, and the size of the information set. ${ }^{8}$ Many studies in the empirical literature on monetary policy transmission are based on small-scale VARs, typically including only around three to ten of the most important macroeconomic aggregates. ${ }^{9}$ Such limited information sets not only often preclude an analysis of additional variables in which the researcher might be interested, such as international data as in this paper, or disaggregated data, but they may also imply omitted variables biases in the estimated parameters, potentially affecting both forecasting and structural analysis. ${ }^{10} \mathrm{~A}$ recurrent problem that is ascribed to omitted variables biases and the exclusion of relevant variables is, for example, the emergence of so-called price puzzles, i.e. the counter-intuitive results of an increase of the price level after surprise contractions of monetary policy. ${ }^{11}$

The fact that many VARs are based on limited information sets is a consequence of the

\footnotetext{
${ }^{8}$ The estimation strategies can be classified into classical and Bayesian methods, while the identification schemes can be classified into methods based on (a) short run restrictions (contemporaneous recursive or non-recursive assumptions, e.g. on monetary authorities' reaction functions), applied, e.g., by Bernanke and Blinder (1992), (b) long-run restrictions (assumptions on the impact of structural shocks in the long-run), applied e.g. by Blanchard and Quah (1989), (c) sign restrictions (assumptions on the dynamic reaction of certain variables at certain horizons, applied, e.g., by Uhlig (2005), or (d) narrative approach (the extraction of signals from additional data such as records of policy-makers' meetings), applied, e.g., by Romer and Romer (1989).

${ }^{9} \mathrm{~A}$ reference study in the literature based on small-scale VARs is Christiano, Eichenbaum, and Evans (1999), based on a system of six variables including real GDP, the GDP deflator, and an index of commodity prices, a short term interest rate, and two measures of reserves.

${ }^{10}$ See Sims (1992), Stock and Watson (2001), Bernanke and Boivin (2003), and Bernanke, Boivin and Eliasz (2005).

${ }^{11}$ See Sims (1992), Christiano, Eichenbaum, and Evans (1999), Bernanke, Boivin and Eliasz (2005), and Forni and Gambetti (2010).
} 
degrees-of-freedom problem or the curse of dimensionality. VARs are generously parameterized and the sample sizes of macroeconomic data are typically limited. Without further restrictions and given traditional, OLS-based estimators or Bayesian estimators with flat priors, only a limited number of parameters can be estimated accurately. While adding additional variables leads to decreased biases in the estimated parameters, improving the in-sample fit of the models, it typically also leads to higher estimation uncertainty, implying poor inference, i.e. inaccurate out-of-sample predictions or impulse response functions in identified VARs. This is known as the curse of dimensionality or the problem of overfitting and is typically due to the multicollinearity of the included regressors, a problem that is especially relevant for macroeconomic time series that are highly correlated. ${ }^{12}$

The literature has proposed several approaches to address the curse of dimensionality. One strand of the literature extracts and summarizes the informational content of larger information sets in a relatively small set of estimated factors and either estimates pure dynamic factor models or combines such factor models with traditional VAR models. ${ }^{13}$ In the monetary policy transmission literature such approaches are, e.g., employed by Bernanke, Boivin and Eliasz (2005), and Forni and Gambetti (2010). A second strand of the literature imposes additional exclusion, exogeneity or homogeneity restrictions in higher-dimensional global or panel VARs so as to effectively limit the number of parameters to be estimated. ${ }^{14}$ In the monetary policy transmission literature this approach is, e.g., applied in the context of a global VAR by Dées et al. (2005). The "Bayesian shrinkage" approach proposed by BGR (2010) is part of a third strand of the literature, adopting an alternative - Bayesian - estimation approach with a particular specification of informative priors. ${ }^{15}$ As mentioned above, this approach has been shown to offer a valid alternative to factor models and global and panel VARs to handle large dynamic systems. ${ }^{16}$ In the monetary policy transmission literature it is applied, e.g., by Beauchemin and Zaman (2011).

A selective review of the main results of the VAR-based monetary policy transmission literature (using both small and large information sets) and the VAR- and non-VAR-based literature on balance-sheet channels of monetary policy can be summarized as follows.

\footnotetext{
${ }^{12}$ See Littermann (1986), Stock and Watson (2001), Leeper, Sims and Zha (1996), and Bernanke, Boivin and Elisaz (2005).

${ }^{13}$ See Stock and Watson (2002, 2005), Bernanke, Boivin and Eliasz (2005), or Forni et al. (2009).

${ }^{14}$ See Pesaran, Schuermann, and Weiner (2004), or Pesaran, Schuermann, and Smith (2009).

${ }^{15}$ See also De Mol, Giannone, and Reichlin (2008) and Koop (2011). Alternative methodologies to set the informativeness of the prior distributions include, e.g., Giannone, Lenza, and Primiceri (2012).

${ }^{16}$ See also De Mol, Giannone, and Reichlin (2008) and Koop (2011). Giannone, Lenza, and Primiceri (2012) have recently proposed an alternative methodology to set the informativeness of the prior distributions.
} 


\subsection{Monetary policy transmission in vector autoregressions}

The results on the impact of monetary policy shocks on aggregate output and different measures of real investment and activity are robust across various estimation strategies, identification schemes and information sets, with the exception of Uhlig (2005) imposing sign restrictions. Most studies detect a negative impact of a surprise monetary contraction on aggregate output, real activity and investment, as well as on real wages and profits. Uhlig (2005), on the other hand, finds no significant reaction of real GDP in response to a monetary policy shock.

The results on prices and exchange rates are mixed. In the literature based on small information sets and recursive identification schemes, several "puzzles" have emerged, namely that contractionary monetary policy shocks imply increases in aggregate price levels, exchange rate depreciations, and delayed overshooting or so-called forward discount bias puzzles. ${ }^{17}$ Cushman and Zha (1997), Kim and Roubini (2000), and Kim (2001a, 2001b) show that price and exchange rate puzzles disappear when non-recursive identification schemes are applied. ${ }^{18}$ However, their identification schemes are not uncontroversial, see, e.g., Faust and Rogers (2003). Furthermore, with a sign restriction approach as employed by Scholl and Uhlig (2008), the delayed overshooting and forward discount puzzles found in the recursive identification literature reappear. Christiano, Eichenbaum, and Evans (1999) show that at least the price puzzle disappears with the inclusion of additional variables (such as a commodity price index) and attribute this fact to an adjustment of the information set of the econometrician to the one of the monetary policy makers, i.e. a reduction in omitted variables biases. Several studies in the literature based on large information sets support this view. Bernanke, Boivin, and Eliasz's (2005) study based on a factor-augmented VAR approach shows that price puzzles are a consequence of the exclusion of conditioning information and that additional conditioning information leads to reasonable responses of both prices and money aggregates. In line with this, Forni and Gambetti (2010) show that a factor model based on a larger information set helps to eliminate both price puzzles and delayed overshooting puzzles of exchange rates. Moreover, they argue that even if small-scale VARs include commodity prices, the estimated reaction of prices to monetary policy is negligible in size and disproportionately small, compared to the large response of output. ${ }^{19}$ In their factor model, the response of prices in the medium run is relatively large and similar in size to that of industrial production, and monetary policy has reasonable effects on different real variables including, e.g., consumption, industrial production, credit, housing starts, and

\footnotetext{
${ }^{17}$ See Sims (1992), Eichenbaum and Evans (1995), and Grilli and Roubini (1995).

${ }^{18}$ Note that Kim (2001b) uses both recursive and non-recursive identification schemes.

${ }^{19}$ See Christiano, Eichenbaum, and Evans (1999).
} 
labor market variables such as hours, employment and vacancies. Beauchemin and Zaman's (2011) study based on the "Bayesian shrinkage" approach proposed by BGR (2010) also ascribes the price puzzles found in the literature to limited information and overfitting problems of classically-estimated, small-scale VARs. However, in contrast to Bernanke, Boivin, and Eliasz (2005) and Forni and Gambetti (2010), they find that the consumer price index is basically unaffected by a monetary shock. In the global VAR framework applied by Dées et al. (2005), price puzzles reappear.

Studies on the trade and current account balance are based on small information sets and yield mixed results. Based on recursive identification schemes, Kim (2001b) and Koray and McMillin (1999) provide evidence for J-curve effects for the US economy, i.e. an initial improvement and subsequent deterioration of the trade balance following a contractionary monetary policy shock. Based on non-recursive identification schemes, Cushman and Zha (1997) provide J-curve evidence for Canada, Kim (2001a) supports the J-curve evidence of Koray and McMillin (2001) for the US, and Kim (2001b) offers evidence of a deterioration of the trade balance in response to a contractionary monetary policy shock for France, Italy, and the UK. ${ }^{20}$ Fratzscher, Saborowski, and Straub (2009) apply a sign restriction approach to study the impact of monetary policy shocks on the composition of US capital flows and the trade balance. Their findings suggest that an exogenous easing of US monetary policy induces net capital inflows and a worsening of the trade balance which they attribute to wealth effects. Lee and Chinn (2006) apply a long-run identification scheme to study the dynamics of the current account and real exchange rates in a bivariate VAR. A temporary shock which they associate with a monetary innovation induces a temporary depreciation of the real exchange rate and a concurrent improvement in the current account.

On wealth channels, Ludvigson, Steindel, and Lettau (2002) use a VAR framework to analyze the consumption-wealth channel in the United States. They find that the household wealth channel plays a minor role in the transmission of monetary policy to consumption. Eickmeier and Hofmann (2013) use a factor-augmented VAR model to analyze the role of monetary policy in the housing and credit boom prior to the global financial crisis. They find that monetary policy shocks have a persistent effect on house prices, real estate wealth and private sector debt. Assenmacher and Gerlach (2008) use individual-country and panel VARs to study the impact of monetary policy shocks on asset prices. Their results show that monetary policy has a large effect on residential property as well as equity prices. They also show that the importance of the financial structure of a country in influencing this impact

\footnotetext{
${ }^{20}$ Note that Kim (2001b) is based on the so-called "marginal" approach, in which a core set of variables is complemented by one additional variable, or group of variables, at a time. As mentioned by BGR (2010), this approach makes comparison of impulse responses across different models problematic.
} 
appears limited. Kaufmann and Valderrama (2010) use a Markov-switching VAR to analyze the role of the interaction between asset prices and credit in the transmission of monetary policy and other shocks to the real economy. In the presence of asymmetric information and other frictions in financial markets, equity serves as a collateral for loans, while the supply of loans influences asset prices by improving investment prospects. Kaufmann and Valderrama's study provides evidence for such reinforcing effects between asset prices and lending in a market-based financial system like the one in the United States, but no evidence for such effects in a bank-based system like the one in the euro area.

\subsection{Balance-sheet and bank lending channels of monetary policy}

The VAR studies on balance-sheet and bank lending channels of monetary policy are mostly based on small information sets and focus on domestic rather than foreign channels. Gertler and Gilchrist $(1993,1994)$ use small-scale VARs to analyze the balance-sheet channel. They analyze the impact of monetary policy on the financial conditions of small versus large firms and find that a monetary policy contraction leads to a relatively larger contraction of borrowing and business activities of small versus large firms, supporting the credit view and highlighting the importance of financial market asymmetries and frictions in monetary transmission.

Bernanke and Blinder (1992) use a small-scale VAR to provide preliminary evidence of a bank lending (or loan supply) channel in the United States. They show that innovations to the federal funds rate affect the composition of bank assets and that, over time, tighter monetary policy reduces the supply of loans. To the extent that some borrowers are dependent on bank loans for credit, this reduced supply of loans can depress the economy. Iacoviello and Minetti (2008) use VARs to analyze balance-sheet and bank lending channels in the housing market of European economies. Their results provide robust evidence of a bank lending channel for Finland and the UK, evidence of a balance-sheet channel for Germany and lack of evidence of both a balance-sheet and bank lending channel for Norway. Ciccarelli, Maddaloni, and Peydró (2010) study the bank lending and balance-sheet channel in a VAR framework using data from bank lending surveys and find that the bank lending channel is stronger than the balance-sheet channel for firms, whereas the latter is stronger for households.

In addition to the these VAR-based studies on balance-sheet and bank lending channels, there are several studies based on cross-section and time series regressions. Bond et al. (2003) use company panel data sets for manufacturing firms in Belgium, France, Germany, and the United Kingdom to study the balance-sheet channel and its relation to the differences in financial systems across countries. They find that cash flows play a significant role in 
explaining company investment spending, suggesting the importance of financial constraints and asymmetric information problems. Comparisons of their results across countries are consistent with the hypothesis that financial constraints on investment are relatively more severe in more market-oriented financial system, such as in the UK, than in more bankbased systems, such as in the continental European countries. Chatelain et al. (2003) use micro firm-level data in the euro area to provide evidence of the relevance of the broad credit (balance-sheet) channel. They find that investment by firms with weaker balance sheets displays higher liquidity sensitivity. Ashcraft and Campello (2007) use a panel of cross-section bank balance-sheet data to provide evidence that the balance-sheet channel is an important part of how monetary policy works, independent from a bank lending channel. Alpanda and Aysun (2012) use cross-section and time series regressions for bank-level data to provide evidence of a balance-sheet channel in the United States and to show that this channel is more effective with increasing bank globalization. Finally, Mishkin (1978) analyzes changes in household balance sheets during the Great Depression and provides evidence of the importance of household balance sheet effects on aggregate demand.

Non-VAR-based studies on the bank lending channel include, e.g., Kashyap, Stein, and Wilcox (1993). To provide evidence on the bank lending channel these authors use biand multivariate Granger causality tests and investment equation estimations. Their study is based on (aggregate) data from the commercial paper market and suggests that contractionary monetary policy can indeed reduce the loan supply of banks and that the loan supply affects firms' investment, even after controlling for interest rates and output. Kashyap and Stein $(1995,2000)$ provide further cross-sectional regression-based evidence on the bank lending channel using disaggregated bank data. They show that the impact of monetary policy on lending is stronger for both smaller and less liquid banks.

\section{Methodology}

The empirical model is defined as the following $\operatorname{VAR}(\mathrm{p})$ model:

$$
Y_{t}=c+A_{1} Y_{t-1}+\ldots+A_{p} Y_{t-p}+u_{t}
$$

where $Y_{t}=\left(y_{1, t}, y_{2, t}, \ldots, y_{n, t}\right)^{\prime}$ is a $n x 1$ vector of the $\mathrm{n}$ variables included in the system, where $c=\left(c_{1}, c_{2}, \ldots, c_{n}\right)^{\prime}$ is a $n x 1$ vector of constants, where $A_{1}, A_{2}, \ldots, A_{n}$ are $n x n$ matrices of the autoregressive parameters, and where $u_{t}$ is a $n x 1$ vector of white noise error terms with a covariance matrix $E\left[u_{t} u_{t}^{\prime}\right]=\Psi$. I estimate model (1) using the Bayesian shrinkage approach proposed by BGR (2010) which, as mentioned above, allows me to include a larger list of 
variables. ${ }^{21}$ In a Bayesian procedure the parameters are treated as random variables and their (posterior) distribution is estimated via the imposition of prior beliefs on their distribution. I follow BGR (2010) by imposing a normal inverted Wishart prior which is a modification of the Minnesota prior. The Minnesota prior was originally developed by Litterman (1986) at the University of Minnesota and the Federal Reserve Bank of Minneapolis and imposes a random walk representation for all variables. This seems to be a reasonable prior assumption for most macroeconomic variables (except the ones characterized by substantial mean reversion). The problem with the Minnesota prior is the imposition of a fixed and diagonal covariance matrix of the residuals which rules out possible correlation among residuals of different variables. Kadiyala and Karlsson (1997) and Robertson and Tallman (1999) therefore suggest a normal inverted Wishart prior that retains the principles of the Minnesota prior but relaxes the assumptions on the covariance matrix structure of the residuals. ${ }^{22}$ The assumptions on the prior distribution can be summarized as follows.

Rewriting the VAR in equation (1) as a system of multivariate regressions yields

$$
Y=X B+U
$$

where $Y=\left(Y_{1}, Y_{2}, \ldots, Y_{T}\right)^{\prime}$ is a $T x n$ matrix where $\mathrm{T}$ is the number of observed time periods, $X=\left(X_{1}, X_{2}, \ldots, X_{T}\right)^{\prime}$ with $X_{t}=\left(Y_{t-1}^{\prime}, Y_{t-2}^{\prime}, \ldots, Y_{t-p}^{\prime}, 1\right)^{\prime}$ is a $T x k$ matrix where $k=n p+1, B=\left(A_{1}, A_{2}, \ldots, A_{p}, c\right)^{\prime}$ is a $k x n$ matrix containing all parameters, and $U=$ $\left(u_{1}, u_{2}, \ldots, u_{T}\right)^{\prime}$ is a $T x n$ matrix of the error terms.

The normal inverted Wishart prior has the form:

$$
\operatorname{vec}(B) \mid \Psi \sim N\left(\operatorname{vec}\left(B_{0}\right), \Psi \otimes \Omega_{0}\right) \text { and } \Psi \sim I W\left(S_{0}, \alpha_{0}\right)
$$

where the prior parameters $B_{0}, \Omega_{0}, S_{0}, \alpha_{0}$ are defined such that the prior expectation and variance of $\mathrm{B}$ coincide with the Minnesota prior expectations and variances for the autoregressive matrices $A_{1}, A_{2}, \ldots, A_{p}$ :

$$
\begin{aligned}
E\left[\left(A_{k}\right)_{i j}\right] & =\left\{\begin{array}{c}
\delta_{i}, j=i, k=1 \\
0, \text { otherwise }
\end{array}\right. \\
V\left[\left(A_{k}\right)_{i j}\right] & =\left\{\begin{array}{c}
\frac{\lambda^{2}}{k^{2}}, j=i \\
\nu \frac{\lambda^{2}}{k^{2}} \frac{\sigma_{i}^{2}}{\sigma_{j}^{2}}, \text { otherwise }
\end{array}\right.
\end{aligned}
$$

\footnotetext{
${ }^{21}$ The description of the methodology in this section closely follows BGR (2010) and retains their notation.

${ }^{22}$ The normal inverted Wishart prior is a so-called natural conjugate prior in the normal regression model, i.e. a prior that combined with the likelihood produces a posterior distribution in the same family. This prior has the desirable property that it can be generated by a sample of the same model.
} 
and the expectation of $\Psi$ is equal to the fixed residual covariance matrix of the Minnesota prior $\Psi=\operatorname{diag}\left(\sigma_{1}^{2}, \sigma_{2}^{2}, \ldots \sigma_{n}^{2}\right)$. The matrices $A_{1}, A_{2}, \ldots, A_{p}$ are assumed to be independent and normally distributed and for the intercepts $c$ an uninformative (so-called "diffuse") prior is assumed. Following BGR (2010) I impose a random walk prior, i.e. $\delta_{i}=1$, for all nonstationary variables, i.e. that the prior mean of the variables is characterized by random walk with drift $Y_{t}=c+Y_{t-1}+u_{t}$, and a white noise prior, i.e. $\delta_{i}=0$, for all stationary variables. The so-called hyperparameter $\lambda$ controls the overall tightness of the prior distribution around the random walk and therefore represents the confidence in the prior distribution with respect to the information contained in the data. If the hyperparameter is set to $\lambda=0$ the posterior is equivalent to the prior, whereas if $\lambda=\infty$ the posterior expectation is equivalent to an OLS estimate. The strategy for choosing the tightness of the priors is explained below. The parameter $1 / k^{2}$ is the rate at which the prior variance decreases with increasing lag length and reflects the prior belief that more recent lags provide more reliable information than more distant ones. In order to have a prior which can be implemented simply, the normal inverted Wishart prior has to be based on the assumption $\nu=1$, i.e. that the variation of a given variable is equally explainable by its own lags and lags of other variables. This condition prohibits the prior from treating lags of the dependent variable differently from lags of other variables (apart from the scale) and is in a sense the price for being able to relax the strict covariance matrix assumption of the Minnesota prior. ${ }^{23}$ The different scale and variability of the data are taken into account by the ratio $\frac{\sigma_{i}^{2}}{\sigma_{j}^{2}}$. These scale parameters are set equal to the variance of the residual from a univariate autoregressive model of order $\mathrm{p}$ for each variable.

It can be shown that the normal inverted Wishart prior can be implemented by extending the system in equation (2) by dummy observations incorporating the parameters of the prior distribution. ${ }^{24}$ The posterior expectation of the parameters are obtained by OLS estimates of the extended system and posterior distributions of the parameters are approximated numerically by a Gibbs sampling algorithm.$^{25}$

\subsection{Setting the tightness}

As formally shown by De Mol, Giannone, and Reichlin (2008), $\lambda$ should be set in relation to the model size, i.e. decreased as the number of variables increases in order to avoid overfitting, namely an increase in the in-sample fit solely due to an increase in the number of regressors.

\footnotetext{
${ }^{23}$ See Robertson and Tallman (1999).

${ }^{24}$ See BGR (2010) for details. Technically, these dummy variables work as a regularization solution to the problem of inverting a large, nearly singular matrix in a classical OLS estimation, i.e. the original system.

${ }^{25}$ In such a Gibbs sampling algorithm, the marginal and joint posterior distributions of the parameters are approximated by repeated random drawings from the conditional posterior distributions of $B$ and $\Psi$.
} 
I follow BGR (2010) and set the overall tightness to yield a desired average in-sample mean squared forecast error for a number of key series included in the VAR specification. For a desired relative in-sample mean squared forecast error, fit, for the three key series real GDP, the GDP deflator, and the short-term interest rate, and for a specified period $t=1$ until $t=T, \lambda$ is chosen such that

$$
\lambda(f i t)=\arg \min _{\lambda}\left|f i t-\frac{1}{3} \sum_{i \in \mathcal{I}} \frac{m s f e_{i}^{(\lambda, m)}}{m s f e_{i}^{(0)}}\right|
$$

where $\mathcal{I}=\{Y, P, i\}$ and $m s f e_{i}^{(\lambda, m)}=\frac{1}{T-p-1} \sum_{t=p}^{T-2}\left(y_{i, t+1 \mid t}^{(\lambda, m)}-y_{i, t+1}\right)^{2}$.

$m s f e_{i}^{(\lambda, m)}$ is the in-sample one-step-ahead mean squared forecast error of a given model specification $m$ (i.e. a given model specification with a given number of variables) evaluated in the sample $t=1, \ldots, T-1$ where $p$ is the order or the lag-length of the model. The $m s f e_{i}^{(\lambda, m)}$ of model $m$ is reported relative to $m s f e_{i}^{(0)}$ which corresponds to the forecast error of a benchmark model where the prior is imposed exactly, i.e. $\lambda=0$. The benchmark model is kept constant across different model specifications $m$, which is why the superscript $m$ is dropped in the notation $m s f e_{i}^{(0)}$ for the benchmark model. A fit smaller than one means that the model with a hyperparameter $\lambda$ has a lower average in-sample mean squared forecast error than the benchmark model where the prior is imposed exactly. I set the benchmark model to a specification including real GDP, the GDP deflator, and the short-term interest rate and the lag length in all specifications to $p=4$. For the baseline estimations, I set $f i t=0.75$, but I check the robustness of the results to estimations imposing a tightness that yields a fit of $0.9,0.5$, and a fit that matches the one of a three variables VAR, estimated by OLS, i.e.

$$
f i t=\left.\frac{1}{3} \sum_{i \in \mathcal{I}} \frac{m s f e_{i}^{(\lambda, m)}}{m s f e_{i}^{(0)}}\right|_{\lambda=\infty, m=S M A L L M O D E L}
$$

\subsection{Data}

The focus of the analysis is on high-income countries which have been under a flexible exchange rate regime over a prolonged time period since the breakdown of the Bretton Woods system in 1973. The two countries included in the sample are the United States and Canada. These two countries are selected due to the availability of quarterly data of the main variables of interest. ${ }^{26}$

\footnotetext{
${ }^{26}$ Taking e.g. the World Bank's "High-income OECD member" country classification and an "interim" or "float" exchange rate regime classification according to Levy-Yeyati and Sturzengegger (2005) already reduces the potential country sample to: Australia, Canada, Japan, Switzerland, and the United States.
} 
Tables B1 and B2 in Appendix B report the data mnemonics, descriptions, sources, specifications, priors and identification schemes. The balanced samples cover the period from Q1 1975 for the United States and Q1 1982 for Canada up to Q4 2007. The sample thus excludes the recent crisis period where interest rates approached the zero lower bound. The baseline model specifications include all variables listed in Tables B1 and B2, respectively, with foreign income flows included either in gross or net terms and as total aggregates or decomposed into different asset categories, such as foreign direct, portfolio and other investment. The specification of the empirical models is motivated by the literature on limited information problems and thus based on more variables than the ones in a typical small-scale VAR. The models include a) the main variables of interest, and b) the variables which are considered most important for the information set of economic agents. The main variables of interest are the gross domestic product deflator, the consumer price index, the producer price index, gross domestic product, aggregate consumption, aggregate investment, net exports, the nominal effective exchange rate, and foreign investment income flows. In order to make the information set of economic agents reasonably comprehensive, the main production, labor market, financial market, money market, and fiscal indicators are added. In particular, I include the unemployment rate, a housing indicator, an industrial production index, a commodity price index, a stock market index, long-term interest rates, non-borrowed and total reserves for the United States and the monetary base for Canada, a monetary aggregate M2, and government expenditures and debt (the latter only for the United States). All variables except interest rates and stock market indices, are either seasonally adjusted at the source or with own calculations based on the X12-ARIMA filter of the US Census Bureau. Logarithms are applied to all series except interest rates (for which raw series are taken). Net foreign income and trade flows are expressed in percent of lagged GDP. GDP is lagged by four quarters in order not to blur the results by monetary policy's impact on GDP. All quantity variables are expressed in constant prices. Real foreign investment income flows are deflated with the CPI. Following BGR (2010) I impose a random walk prior for all variables except the ones characterized by substantial mean reversion, including housing starts and the variables expressed in percent of GDP, i.e. net income and trade flows and government debt. For these variables a white noise prior is imposed.

\subsection{Identification}

For the identification of monetary policy shocks I use a recursive scheme where exogenous monetary policy shocks are identified from a Cholesky decomposition of the variance covari- 
ance matrix of the reduced-form residuals in model (2) ${ }^{27}$ An important assumption behind such an identification is that the information set of the econometrician for the forecasting model (2) and the structural model are the same, which makes it important to include a dataset which sufficiently approximates the information set of economic agents. Together with the assumption of rational expectations, this assumption implies that the forecast errors of the econometrician are equivalent to the forecast errors of the economic agents. With enough identifying assumptions, the forecast errors, i.e. the reduced-form residuals in model $(2), u_{t}$, can be mapped into the structural shocks of the economic model, $e_{t}$. In a recursive identification scheme the following assumptions are imposed on the structural model:

$$
\mathcal{A}_{0} Y_{t}=\mu+\mathcal{A}_{1} Y_{t-1}+\ldots+\mathcal{A}_{p} Y_{t-p}+e_{t}
$$

where $\mu=C^{-1} c, \mathcal{A}_{0}=C^{-1}, \mathcal{A}_{j}=C^{-1} A_{j}$ for $j=1, \ldots, p, e_{t}=C^{-1} u_{t}$, $C D C^{\prime}=E\left[u_{t} u_{t}^{\prime}\right]=\Psi, D=\operatorname{diag}(\Psi)$, and $e_{t} \sim W N(0, D)$.

The diagonal matrix $\mathrm{D}$ incorporates the assumption that the structural monetary policy shocks are orthogonal to all other shocks in the economy. They are assumed to be a linear transformation $e_{t}=C^{-1} u_{t}$ of the reduced form residuals where $C D^{1 / 2}$ is the $n x n$ lower diagonal Cholesky decomposition of the covariance matrix $\Psi$ of the reduced form residuals. This implies the restriction $\mathcal{A}_{0}=C^{-1}$ on the structural model, which given the ordering of the variables in $Y_{t}=\left(y_{1, t}, y_{2, t}, \ldots, y_{m-1, t}, y_{m, t}, y_{m+1, t}, \ldots, y_{n, t}\right)^{\prime}$ incorporates the following assumptions. If the monetary policy instrument is included in the $m t h$ position, the variables $y_{i, t}$ with $i=1, \ldots m-1$ are considered to be slow-moving or pre-determined and the variables $y_{i, t}$ with $i=m+1, \ldots n$ are considered to be fast-moving. The slow-moving or predetermined variables are assumed not to react contemporaneously to the monetary policy shocks, but are in the information set of the policy makers when setting the monetary policy instrument, while the fast-moving variables are assumed not to be taken into account by the policy makers when deciding on the instrument, but can potentially be affected by the monetary policy shock contemporaneously.

Given the estimates of the autoregressive parameters in model (2) and the covariance matrix of the reduced-form residuals, one can calculate the Cholesky decomposition $C D^{1 / 2}$ and the matrix $C$ by means of which the impulse response functions to the structural monetary policy shocks can be derived. ${ }^{28}$

\footnotetext{
${ }^{27}$ Note that the focus is on exogenous shocks to monetary policy rather than monetary policy actions per se, as the propagation of shocks is the only valid experiment to identify the independent effect of monetary policy. Monetary policy decisions per se are in part the result of a systematic response of monetary policymakers to developments in the economy and therefore reflect the response of the economy to a combination of different shocks (see Bernanke and Mihov, 1998).

${ }^{28}$ Rewriting the estimated model (2) in companion matrix form yields: $\mathcal{Y}_{t}=E+\digamma \mathcal{Y}_{t-1}+\mathcal{U}_{t}$ where $\mathcal{Y}_{t}=$
} 
In the given dataset, the identification scheme is based on the assumption that the monetary policy instrument is the short-term interest rate. All financial market variables, i.e. long-term interest rates, exchange rates, stock market indices, reserves and monetary aggregates, are considered to be fast-moving variables. All other variables, i.e. all price indices, real domestic aggregates, government expenditures and debt, foreign trade and investment income flows, the unemployment rate, and the housing and industrial price indices, are considered to be slow-moving. A comparison of the results based on a recursive identification scheme to results based on alternative schemes, such as sign restrictions, is beyond the scope of this paper. However, I check the robustness of the results to estimations based on a few alternative recursive identification schemes.

\section{Results}

The baseline results are reported in Appendix C. All figures report the impulse response functions to a contractionary monetary policy shock, i.e. a positive shock in the policy rate (the Federal funds rate in the United States and the overnight money market rate in Canada) of one hundred basis points. The confidence bands for the impulse response functions are reported at the 68 percent confidence level, i.e. at the 16 th and 84 th percentiles of the posterior distribution of the impulse response functions. They are computed with a Gibbs sampling algorithm, approximating the posterior distribution of the impulse response functions by Monte Carlo simulations. ${ }^{29}$ For each country I analyze four specifications, differing with respect to the specification of foreign investment income flows. The first specification includes total gross flows, the second total net flows, the third decomposed gross flows, and the fourth decomposed net flows. All baseline estimations are based on the priors and the identification scheme discussed in Section 3 above and a tightness that yields

$\left.\overline{\left(Y_{t}^{\prime}, Y_{t-1}^{\prime}, \ldots, Y_{t-p+1}^{\prime}\right)^{\prime} \text { and } \mathcal{Y}_{t-1}=\left(Y_{t-1}^{\prime}, Y_{t-2}^{\prime}\right.}, \ldots, Y_{t-p}^{\prime}\right)^{\prime}$ are $n p x 1$ matrices, where $\mathcal{U}_{t}=\left(u_{t}^{\prime}, u_{t-1}^{\prime}, \ldots, u_{t-p+1}^{\prime}\right)^{\prime}$ is a $n p x 1$ matrix, and where $F$ is the following $\mathrm{np} \times \mathrm{xp}$ matrix:

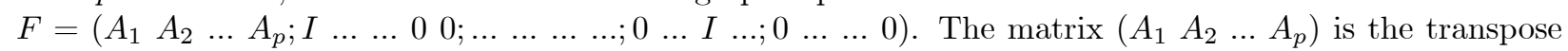
of the estimated $B$ matrix from the SUR representation (equation 2 above), disregarding the last $1 \times \mathrm{n}$ row vector of estimated constants. Recursive substitution yields $\mathcal{Y}_{t}=\left(E+F E+F^{2} E+\ldots+F^{k} E\right)+$ $\left(\mathcal{U}_{t}+F \mathcal{U}_{t-1}+F^{2} \mathcal{U}_{t-2}+\ldots F^{k} \mathcal{U}_{t-k}\right)+F^{k+1} \mathcal{Y}_{t-k-1}$ where the last term disappears under the assumption of covariance stationarity letting $k \rightarrow \infty$. Extracting the subset of interest of $\mathcal{Y}_{t}$ a transformation matrix $\mathrm{J}$ of dimension $n x n p$ is defined as $J=\left(I_{n} 0 \ldots 0\right)$. The effects of a one-unit increase of the reduced-form residuals at different horizons $j$ on $Y_{t}$ can then be defined as $\psi_{j}=J F^{j} J^{\prime}$. Given the above identification scheme, the effects of one-unit structural shocks occurred $j$ periods ago on the variables of the vector $Y_{t}$ are $\psi_{j}=J F^{j} J^{\prime} C$. For a given lag $j$ the $i m$-th component of the matrix $\psi_{j}$ identifies the impact of a monetary policy shock occurred $j$ periods ago on the $i$ th variable in the system.

${ }^{29}$ I take 200 draws from the posterior distribution of the VAR coefficients and the covariance matrix, from which I obtain 200 estimates of the Cholesky decomposition $C D^{1 / 2}, C$, and the structural parameters $\mathcal{A}_{j} s$. For each draw I compute the impulse response function, order them and extract the 68 and 90 percent bands (see e.g. Canova, 1991, and Gordon and Leeper, 1994). 
an overall fit of $0.75 .^{30}$

In order to make the analysis comparable to the existing literature, I start by discussing the results on the variables included in previous studies and the main additional economic indicators before moving on to the results on foreign investment income.

\subsection{Prices, exchange rates, and real activity}

A first important result is the elimination of price puzzles often found in the literature based on small-scale VARs. In a large BVAR framework as used here, these price puzzles disappear in the estimations for both countries (see Figures C1 to C8), supporting the evidence presented by BGR (2010). A contractionary monetary policy shock, i.e. a positive surprise increase in the policy rate, reduces the GDP deflator, the CPI, the PPI, and the COMPI. The estimations for the United States display a very small increase of the CPI (and PPI) on impact, but the effect dies out after three to four quarters. Comparing these results to the ones obtained with small-scale VARs suggests that the elimination of price puzzles might indeed be due to the enlargement of the information set and that adding only one or two variables such as an index of commodity prices might not be enough to get rid of the puzzles. Figures D1 and D3 report the results of a three-variables VAR, while Figures D2 and D4 report the results of a seven-variables VAR comparable to the specification of Christiano et al. (1999). As can be seen in all these figures, and in contrast to the baseline specifications including up to 26 variables, such small-scale VARs still display considerable increases in price levels following a surprise monetary contraction. Thus, although these two central banks today certainly track a much larger set of indicators than just the 26 of the most important macroeconomic aggregates included here, models of this size already appear to approximate the information set of these two monetary authorities reasonably well and arguably much better than the small models including only a handful of variables.

In line with the results on prices, the results on exchange rates suggest that a large BVAR approach can also be successful in eliminating "delayed overshooting" or "forward discount bias" puzzles. In the United States, a positive interest rate innovation induces a statistically significant nominal effective exchange rate appreciation of a little less than 1 percent on impact followed by a depreciation thereafter, which is in line with theoretical predictions from interest rate parity conditions. In Canada, the response is less pronounced, less significant and more delayed, with the exchange rate appreciation reaching a peak of about 0.5 percent after only a year.

The results on real domestic activity confirm the findings in the existing literature (with

\footnotetext{
${ }^{30}$ For the specification in total gross flows, the overall tightness of the priors $(\lambda)$ for such a fit is 0.16 for the estimations for the United States, and 0.17 for the estimations for Canada.
} 
the exception of Uhlig (2005) as discussed in the literature review above). A contractionary monetary policy shock leads to a statistically highly significant reduction of real consumption, investment, and GDP. In both countries, the impact on investment, consumption and GDP reaches about $1,0.2$ and 0.3 percent respectively.

Monetary policy's impact on net trade flows is ambiguous and not fully in line with the results of previous studies. In the United States, the surprise monetary policy contraction leads to a slight, and marginally significant, improvement of the trade balance, followed by a deterioration after about one and a half years, pointing to J-curve effects found in the literature. In Canada, the trade balance improves after a monetary policy shock (by a statistically significant 0.2 percent) before moving back to the equilibrium, but it never deteriorates. Cushman and Zha's (1997) evidence of J-curve effects in Canada are thus not confirmed in the present estimations.

\subsection{Additional economic indicators}

The results on production, labor, financial, money market, and fiscal indicators are mostly in line with expectations (see Figures C1 to C8). In the United States, the contractionary monetary policy shock leads to a statistically significant increase in the unemployment rate of a little more than 0.1 percent and a reduction in housing starts of about two percent. The contractionary monetary policy shock is also followed by a short-lived decrease of about one percent in the S\&P 500. If changes in households' and firms' wealth and financial positions affect their spending and investment decisions (in the credit view through effects on balance sheets and the terms of credit), then these results suggest that wealth and domestic balance-sheet credit channels might also be an effective channel through which monetary policy affects the domestic economy. Long-term interest rates increase by a little less than 0.1 percent on impact and decrease back to the equilibrium after about two quarters. As expected with a contractionary monetary policy shock, non-borrowed reserves decrease by about one percent on impact. This decrease is, however, followed by a statistically significant increase in the second year after the shock. Government expenditures, arguably in order to offset the contractionary monetary policy move, increase by about 0.1 percent for roughly a year, and government debt increases up to about 0.2 percent after two years.

The results for Canada are in line with the results for the United States, but, generally, somewhat more pronounced. The contractionary monetary policy shock leads to a statistically significant increase in the unemployment rate of about 0.2 percent and a reduction in housing starts of about three percent. The contractionary monetary policy shock is also followed by a statistically significant decline of the S\&P/TSX 60 of about 3 percent. Long 
term interest rates increase by about 0.2 percent on impact before returning back to the equilibrium after about two years, and both M0 and M2 display a small and persistent decline (about 0.2 percent in both cases). However, government expenditures do not react significantly after a surprise monetary contraction.

\subsection{Foreign investment income}

The results on foreign investment income flows show that monetary policy shocks have a statistically and economically significant impact on both gross and net foreign investment income flows on both countries. The impact differs considerably across asset categories. For certain categories, such as foreign direct investment, it can be large. The impact also differs over time. In the short run, effects on interest income or exchange rate valuation effects appear to dominate, while in the medium run effects on dividend income appear to be the main driver.

Figures C1 and C5 report the results of the specifications with total gross flows for the two countries respectively. In the United States a surprise monetary contraction induces, on impact, a statistically significant increase of about one percent of both foreign income receipts and payments. This impact increase is followed by a statistically significant fall of about two percent of both receipts and payments after a year. In Canada, a surprise monetary contraction leads to a fall of receipts and payments already on impact. This fall amounts to about one percent on impact and, again, about two percent after a year.

An impact increase of foreign investment income receipts, i.e. receipts from domestically owned assets abroad, could be due to an increase of interest income, which, in turn, could be due to the fact that the domestic monetary policy contraction is followed (or expected to be followed) by monetary contractions abroad. An impact rise is unlikely to be due to exchange rate valuation effects, as a domestic monetary contraction typically implies an appreciation of the domestic currency, which, in turn, would result in a fall, rather than a rise, of the domestic currency value of foreign currency denominated income from abroad. On the other hand, if most of the domestically-owned assets abroad are denominated in domestic currency then exchange rate valuation effects cannot have a large effect. The impact increase of US foreign investment income is therefore most likely due to a rise in interest income rather than exchange rate valuation effects and suggests that US-owned assets abroad are mostly denominated in US dollars. The impact fall of foreign investment income in Canada, on the other hand, is likely to be due to exchange rate valuation effects and the fact that most Canadian-owned assets abroad are denominated in foreign currencies. The fall in foreign investment income receipts detected after about a year in both countries, could be due to 
the fall of dividend income receipts, which, in turn, could be due to the negative impact of the domestic (or the subsequent foreign) monetary policy contractions on foreign economies (and thus foreign firms' profits and dividend payments); this could materialize with a brief time lag. It could also be due to portfolio rebalancing effects. A surprise rise in domestic interest rates could lead to a rebalancing away from foreign into domestic assets, which could reduce the income earned from domestically owned assets abroad.

For changes in foreign investment income payments, i.e. payments on foreign-owned domestic assets, exchange rate valuation effects cannot be predominant as foreign-owned domestic assets in Canada and the United States are unlikely to be denominated in foreign currencies. The impact rise in foreign investment income payments in the United States is most likely due to a rise in interest payments following the surprise rise in the monetary policy rate, while the fall in foreign investment income payments detected after about a year in both countries could be due to a fall in domestic dividend payments due to the contractionary effect of the monetary policy shock on the domestic economy (and domestic firms' profits and dividend payments).

Figures $\mathrm{C} 3$ and $\mathrm{C} 7$ report the specifications with gross foreign investment income flows further decomposed. In the United States, the data on foreign investment income flows are decomposed into a private direct, a government, and a private other investment category. The results from these decompositions show that the impact rise in total foreign investment income receipts must mostly be due to monetary policy's impact on foreign other investment receipts. This confirms the conjecture above that most of the impact rise is due to a rise in interest income receipts, which should be the predominant source of income for the foreign other investment category that consists mostly of debt rather than equity instruments. Also the above interpretation on the impact rise in total US foreign investment income payments appears to be in line with the results based on further asset decompositions. According to the results based on these decompositions, the impact rise in total US foreign investment income payments is driven by the impact on changes in payments in the private other and government investment category, which are again likely to consist mostly of debt instruments and thus to be dominated by interest payments. The effects on decomposed gross flows after about a year in the United States are mostly driven by the foreign direct investment category and thus likely by changes in dividend receipts and payments. This is again in line with the interpretations above. The decomposed estimations in Canada show that the impact fall in both total foreign investment income receipts and payments are driven by the foreign direct investment category. The fall in receipts could, as discussed above, be due to negative exchange rate valuation effects, while the fall in payments could be due to a fall in dividend payments for equity instruments. The effect on receipts and payments thereafter is difficult 
to ascribe to a specific category.

Figures $\mathrm{C} 2$ and $\mathrm{C} 6$ as well as $\mathrm{C} 4$ and $\mathrm{C} 8$ report the results for total and decomposed net flows. A surprise monetary contraction leads to a statistically significant decline of total net foreign income of 0.025 percent of GDP in the United States after about a year (Figure C2). The impact in the period of the shock is statistically insignificant, showing that the above detected impact increases of foreign investment income receipts and payments offset each other. The total net fall after about a year is driven by a fall in net foreign direct investment income (Figure C6). In Canada, a surprise monetary policy contraction induces a very short-lived decline of 0.05 percent of GDP after about half a year (Figure C6). The specifications with decomposed net flows for Canada do not yield conclusive results and it is thus difficult to ascribe the total net fall of Canadian foreign investment income to a specific asset category.

\subsection{Robustness checks}

I check the robustness of the baseline estimations reported in Appendix $\mathrm{C}$ to estimations imposing a tightness that yields alternative fits, estimations additionally imposing a prior on the sum of coefficients, and estimations based on alternative (recursive) identification schemes (see Appendix E).

The estimations imposing a tightness that yields alternative fits and the estimations additionally imposing a prior on the sum of coefficients are reported in Figures E1 to E4. All reported estimations are based on the specification with gross foreign income flows. Figures E1 and E2 report the estimations imposing a shrinkage parameter that matches the fit of a three-variables model (including the GDP deflator, GDP, and short-term interest rates) estimated by OLS. The fit in such a small VAR is 0.52 for the estimations for the United States and 0.56 for Canada, while the overall tightness of the priors $(\lambda)$ for these fits is 0.04 and 0.06 for the United States and Canada respectively, compared to a tightness of 0.16 and 0.17, for the United States and Canada, respectively, in the same specifications of the baseline estimations above. Qualitatively, the results are unaffected, but generally a little less precise (the impact on the nominal effective exchange rate becomes insignificant in the estimations for Canada). ${ }^{31}$

Figures E3 and E4 report the estimations additionally imposing a prior on the sum of coefficients. This prior takes the form of system-wide restrictions that shrink the sum of coefficients on the lags of the dependent variable in each equation of the VAR to one and

\footnotetext{
${ }^{31}$ In unreported estimations (available upon request), I also checked estimations imposing shrinkage parameters that yield overall fits of 0.9 and 0.5 , respectively. Qualitatively, the results are again unaffected and a little less precise.
} 
the coefficients on lags of other variables to zero. Such a prior amounts to imposing unit roots in first differences of the data and can be interpreted as "inexact differencing." If the prior is imposed exactly, i.e. there is "exact differencing," the model can be expressed entirely in terms of differenced data. In such a limiting form, there are as many unit roots as variables and the differenced data converge to their sample average values. ${ }^{32}$ I follow the implementation of BGR (2010) and set a loose prior with $\tau=10 \lambda{ }^{33}$ Note that the reaction of all variables is qualitatively the same with the exception of the reaction of the NEER in the United States, where the "delayed overshooting" puzzle is restored. Furthermore, in the estimation for Canada, the reactions of the GDP deflator, the CPI, and the NEER become insignificant.

The identification of the monetary policy shock in the baseline estimations reported in Appendix C (as well as the estimations based on small-scale VARs in Appendix D and the robustness checks in Figures E1 to E4) are based on the scheme described in Section 3 above. The assumptions that this scheme implies for certain variables, such as exchange rates, can be questioned. In the baseline estimations I ascribe exchange rates to the fast-moving category. This is a priori the most reasonable assumption in a recursive scheme. Exchange rates are financial market variables which can certainly react contemporaneously to a monetary policy shock. However, this also implies that exchange rates are not included in the information set of the monetary authority. Even if the monetary authority is not explicitly targeting the exchange rate, this might be a questionable assumption, especially for a small open economy like Canada. Such questionable identifying assumptions are a general issue and apply to all identification schemes employed in the literature. ${ }^{34}$ As mentioned above, a comparison of the results based on a recursive identification scheme to results based on alternative schemes, such as sign restrictions, is beyond the scope of this paper. However, I check the robustness of the results to estimations based on two alternative recursive identification schemes (see Figures E5 to E8), namely a scheme where the nominal effective exchange rate is assumed to be slow instead of fast moving, and a scheme where foreign investment income flows are assumed to be slow instead of fast moving. The second scheme is analyzed, as foreign investment income flows are the main focus of this study. It is thus important to see whether different orderings of these flows materially affect the identified effects. The results based on the first scheme are qualitatively unaffected (see Figures E5 and E6). However, some of the effects, in particular the effect on the price indices, become insignificant. In the results based on the second scheme the impact on all variables is unaffected, with the exception of

\footnotetext{
${ }^{32}$ This prior has been developed by Doan, Litterman, and Sims (1984). For further details see also Sims and Zha (1998) and Robertson and Tallman (1999).

${ }^{33}$ See BGR (2010) for further details.

${ }^{34}$ See Faust and Rogers (2003) for an overview.
} 
foreign investment income flows (see Figures E7 and E8). This result shows, as expected, that part of foreign investment income consists of fast-moving financial market variables, such as exchange rates, which react contemporaneously to a monetary policy shock. ${ }^{35}$

\section{Conclusions}

This paper uses a large BVAR framework based on the approach proposed by BGR (2010) to assess the transmission of monetary policy and, in particular, its impact on foreign investment income flows. By analyzing monetary policy's impact on foreign investment income, the paper investigates the potential relevance of foreign balance-sheet channels of monetary policy. The paper provides three main findings. First, a surprise monetary policy contraction has a statistically and economically significant effect on both gross and net foreign investment income flows in both the United States and Canada. While this result does not provide evidence on the independent effect of foreign balance-sheet channels of monetary policy, it provides preliminary evidence that such channels might be increasingly relevant. Second, the decomposition of foreign investment income flows suggests that the impact differs considerably across asset categories and over time, suggesting that the investment instruments and the currency denomination of a country's foreign assets and liabilities could be important for the way in which monetary policy is transmitted to the domestic economy. Finally, a contractionary monetary policy shock induces decreases in aggregate price levels, exchange rate appreciations and reasonable responses for real and financial indicators, which supports existing evidence on the effectiveness of large VARs and the Bayesian shrinkage approach in addressing the curse of dimensionality and eliminating price and exchange rate puzzles.

\footnotetext{
${ }^{35}$ In unreported estimations (available upon request) I also check a scheme where the money supply M2 is assumed to be slow instead of fast moving. While part of the money supply M2 can, again, certainly react contemporaneously to a monetary policy shock (the monetary base, which is controlled by the monetary authority, should by definition be able to react contemporaneously), it might not be appropriate to assume that the monetary authority disregards the money supply M2 in its decision-making process. The results based on the alternative scheme where M2 is slow moving are again equivalent to the results based on the baseline scheme.
} 


\section{References}

[1] Alpanda, Sami, and Uluc Aysun, 2012. "Global Banking and the Balance Sheet Channel of Monetary Transmission," International Journal of Central Banking, 8(3), 141-75.

[2] Ashcraft, Adam B., and Murillo Campello, 2007. "Firm balance sheets and monetary policy transmission," Journal of Monetary Economics, 54, 1515-28.

[3] Assenmacher-Wesche, Katrin, and Stefan Gerlach, 2008. "Financial Structure and the Impact of Monetary Policy on Asset Prices," Swiss National Bank Working Papers, 2008-16.

[4] Banbura, Marta, Domenico Giannone, and Lucrezia Reichlin, 2010. "Large Bayesian Vector Autoregressions," Journal of Applied Econometrics, 25, 71-92.

[5] Beauchemin, Ken, and Saeed Zaman, 2011. "A Medium Scale Forecasting Model for Monetary Policy," Federal Reserve Bank of Cleveland Working Paper, 11-28.

[6] Bernanke, Ben S., and Alan S. Blinder, 1992. "The Federal Funds Rate and the Channels of Monetary Transmission," The American Economic Review, 82(4), 901-21.

[7] Bernanke, Ben S., and Jean Boivin, 2003. "Monetary policy in a data-rich environment," Journal of Monetary Economics, 50, 525-46.

[8] Bernanke, Ben S., Jean Boivin, and Piotr Eliasz, 2005. "Measuring the Effects of Monetary Policy: A Factor-Augmented Vector Autoregressive (FAVAR) Approach," The Quarterly Journal of Economics, 120(1), 387-422.

[9] Bernanke, Ben S., and Mark Gertler, 1995. "Inside the Black Box: The Credit Channel of Monetary Policy Transmission," The Journal of Economic Perspectives, 9(4), 27-48.

[10] Bernanke, Ben S., Mark Gertler, and Simon Gilchrist, 1996. "The Financial Accelerator and the Flight to Quality," The Review of Economics and Statistics, 78(1), 1-15.

[11] Bernanke, Ben S., and Ilian Mihov, 1998. "Measuring Monetary Policy," The Quarterly Journal of Economics, 113 (3), 869-902.

[12] Blanchard, Olivier, and Danny Quah, 1989. "The Dynamic Effects of Aggregate Demand and Supply Disturbances," The American Economic Review, 79(4), 655-73.

[13] Bloor, Chris, and Troy Matheson, 2009. "Real-time conditional forecasts with Bayesian VARs: An application to New Zealand," Reserve Bank of New Zealand Discussion Paper Series, DP/2009/02. 
[14] Boivin, Jean, and Marc Giannoni, 2002. "Has Monetary Policy Become Less Powerful?," Federal Reserve Bank of New York Staff Reports, 144.

[15] Bond, Stephen, Julie A. Elston, Jacques Miaresse, and Benoît Mulkay, 2003. "Financial Factors and Investment in Belgium, France, Germany, and the United Kingdom: A Comparison using Company Panel Data," The Review of Economics and Statistics, $85(1), 153-65$.

[16] Canova, Fabio, 1991. "The Sources of Financial Crisis: Pre- and Post-Fed Evidence," International Economic Review, 32(3), 689-713.

[17] Carriero, Andrea, George Kapetanios, and Massimiliano Marcellino, 2009. "Forecasting exchange rates with a large Bayesian VAR," International Journal of Forecasting, 25, 400-17.

[18] Chatelain, Jean-Bernard, Andrea Generale, Ignacio Hernando, Ulf von Kalckreuth, and Philip Vermeulen, 2003. "New Findings on Firm Investment and Monetary Transmission in the Euro Area," Oxford Review of Economic Policy, 19(1), 73-83.

[19] Christiano, Lawrence J., Eichenbaum, Martin, and Charles L. Evans, 1999. "Monetary Policy Shocks: What Have We Learned and to What End?," in John B. Taylor and Michael J. Woodford, Handbook of Macroeconomics, Amsterdam: Elsevier, 65-148.

[20] Ciccarelli, Matteo, Angela Maddaloni, and José-Luis Peydró, 2010. "Trusting the Bankers: A New Look at the Credit Channel of Monetary Policy," European Central Bank Working Papers, 1228.

[21] Cushman, D.O., and Tao Zha, 1997. "Identifying monetary policy in a small open economy under flexible exchange rates," Journal of Monetary Economics, 39, 433-48.

[22] Dées, Stéphane, Filippo di Mauro, M. Hashem Pesaran, and L. Vanessa Smith, 2007. "Exploring the international linkages of the Euro Area: A Global VAR Analysis," Journal of Applied Econometrics, 22, 1-38.

[23] De Mol, Christine, Domenico Giannone, and Lucrezia Reichlin, 2008. "Forecasting using a large number of predictors: Is Bayesian shrinkage a valid alternative to principal components?," Journal of Econometrics, 146, 318-28.

[24] Doan, Thomas, Robert Litterman, and Christopher A. Sims, 1984. "Forecasting and Conditional Projection Using Realistic Prior Distributions," Econometric Reviews, 3, 1-100. 
[25] Eichenbaum, Martin, and Charles L. Evans, 1995. "Some Empirical Evidence on the Effects of Shocks to Monetary Policy on Exchange Rates," The Quarterly Journal of Economics, 110(4), 975-1009.

[26] Faust, Jon, and John H. Rogers, 2003. "Monetary policy's role in exchange rate behavior," Journal of Monetary Economics, 50, 1403-24.

[27] Forni, Mario, Domenico Giannone, Marco Lippi, and Lucrezia Reichlin, 2009. "Opening the Black Box: Structural Factor Models with large Cross-Sections," The Review of Economics and Statistics, 82, 830-840.

[28] Forni, Mario, and Luca Gambetti, 2010. "The dynamic effects of monetary policy: A structural factor model approach," Journal of Monetary Economics, 57, 203-16.

[29] Fratzscher, Marcel, Christian Saborowski, and Roland Straub, 2009. "Monetary Policy Shocks and Portfolio Choice," European Central Bank Working Paper Series, 1122, 3-48.

[30] Gertler, Mark, and Simon Gilchrist, 1993. "The Role of Credit Market Imperfections in the Monetary Transmission Mechanism: Arguments and Evidence," Scandinavian Journal of Economics, 95(1), 43-64.

[31] Gertler, Mark, and Simon Gilchrist, 1994. "Monetary Policy, Business Cycles, and the Behavior of Small Manufacturing Firms," Quarterly Journal of Economics, 109(2), 30940.

[32] Giannone, Domenico, Michele Lenza, and Giorgio E. Primiceri, 2012. "Prior Selection for Vector Autoregressions," NBER WP 18467.

[33] Giannone, Domenico, Michele Lenza, and Lucrezia Reichlin, 2008. "Explaining the Great Moderation: It is not the shocks," Journal of the European Economic Assocation, $6(2-3), 621-633$.

[34] Ghironi, Fabio, Talan B. Iscan, and Alessandro Rebucci, 2008. "Net foreign asset positions and consumption dynamics in the international economy," Journal of International Money and Finance, 27, 1337-59.

[35] Grilli, Vittorio and Nouriel Roubini, 1996. "Liquidity models in open economies: Theory and empirical evidence," European Economic Review, 40, 847-59. 
[36] Gordon, David B., and Eric M. Leeper, 1994. "The Dynamic Impacts of Monetary Policy: An Exercise in Tentative Identification," Journal of Polical Economy, 102(6), 1228-47.

[37] Iacoviello, Matteo, and Raoul Minetti, 2008. "The credit channel of monetary policy: Evidence from the housing market," Journal of Macroeconomics 30, 69-96.

[38] Kadiyala, K. Rao, and Sune Karlsson, 1997. "Numerical Methods for Estimation and Inference in Bayesian VAR-Models," Journal of Applied Econometrics, 12, 99-132.

[39] Kashyap, Anil K., and Jeremy C. Stein, 1995. "The impact of monetary policy on bank balance sheets," Carnegie-Rochester Conference Series on Public Policy, 42, 151-95.

[40] Kashyap, Anil K., and Jeremy C. Stein, 2000. "What Do a Million Observations on Banks Say About the Transmission of Monetary Policy," The American Economic Review, 90(2), 407-28.

[41] Kashyap, Anil K., Jeremy C. Stein, and David W. Wilcox, 1993. "Monetary Policy and Credit Conditions: Evidence from the Composition of External Finance," The American Economic Review, 83(1), 78-98.

[42] Kaufmann, Sylvia, and Maria Teresa Valderrama, 2010. "The Role of Credit Aggregates and Asset Prices in the Transmission Mechanism: A Comparison between the Euro Area and the USA," The Manchester School, 78(4), 345-77.

[43] Kim, Soyoung, 2001a. "Effects of monetary policy shocks on the trade balance in small open European countries," Economic Letters, 7, 197-203.

[44] Kim, Soyoung, 2001b. "International transmission of U.S. monetary policy shocks: Evidence from VAR's," Journal of Monetary Economics, 48, 339-72.

[45] Kim, Soyoung and Nouriel Roubini, 2000. "Exchange rate anomalies in industrial countries: A solution with a structural VAR approach," Journal of Monetary Economics, $45,561-86$.

[46] Koray, Faik and W. Douglas McMillin, 1999. "Monetary shocks, the exchange rate, and the trade balance," Journal of International Money and Finance, 18, 925-40.

[47] Koop, Gary, 2011. "Forecasting with Medium and Large Bayesian VARs," Journal of Applied Econometrics, 28, 177-203. 
[48] Lane, Philip R., and Gian-Maria Milesi-Ferretti, 2007. "The external wealth of nations mark II: Revised and extended estimates of foreign assets and liabilities, 1970-2004," Journal of International Economics, 73, 223-50.

[49] Lee, Jaewoo, and Menzie D. Chinn, 2006. "Current account and real exchange rate dynamics in the G7 countries," Journal of International Money and Finance, 25, 257274.

[50] Leeper, Eric M., Christopher A. Sims, and Tao Zha, 1996. "What Does Monetary Policy Do?," Brookings Papers on Economic Activity, 2, 1-78.

[51] Levy-Yeyati, Eduardo, and Federico Sturzenegger, 2005. "Classifying exchange rate regimes: Deeds vs. words," European Economic Review, 49, 1603-35.

[52] Litterman, Robert B., 1986, "Forecasting With Bayesian Vector Autoregressions - Five Years of Experience," Journal of Business and Economic Statistics, 4(1), 25-38.

[53] Ludvigson, Sydney, Charles Steindel, and Martin Lettau, 2002. "Monetary Policy Transmission through the Consumption-Wealth Channel," FRBNY Economic Policy Review, May, 117-33.

[54] Mishkin, Frederic S., 1978, "The Household Balance Sheet and the Great Depression," The Journal of Economic History, 38(4), 918-37.

[55] Mishkin, Frederic S., 1995. "Symposium on the Monetary Transmission Mechanism," The Journal of Economic Perspectives, 9(4), 3-10.

[56] Pesaran, M. Hashem, Til Schuermann, and Scott M. Weiner, 2005. "Modeling Regional Interdependencies Using a Global Error-Correcting Macroeconometric Model," Journal of Business and Economic Statistics, 22(2), 129-62.

[57] Pesaran, M. Hashem, Til Schuermann, and L. Vanessa Smith, 2009. "Forecasting economic and financial variables with global VARs," International Journal of Forecasting, $25,642-75$.

[58] Robertson, John C., and Ellis W. Tallman, 1999. "Vector Autoregressions: Forecasting and Reality," Federal Reserve Bank of Atlanta Economic Review, First Quarter, 4-18.

[59] Romer, Christina, and David Romer, 1989. "Does Monetary Policy Matter? A New Test in the Spirit of Friedman and Schwartz," in Olivier Blanchard and Stanley Fischer, eds., NBER Macreconomics Annual, Cambridge MA: MIT Press, 121-84. 
[60] Scholl, Almuth, and Harald Uhlig, 2008. "New evidence on the puzzles: Results form agnostic identification on monetary policy and exchange rates," Journal of International Economics, 76, 1-13.

[61] Sims, Christopher A., 1992. "Interpreting the macroeconomic time series facts," European Economic Review, 36, 975-1011.

[62] Sims, Christopher A., James H. Stock, and Mark W. Watson, 1990. "Inference in Linear Time Series Models with some Unit Roots," Econometrica, 58(1), 113-44.

[63] Sims, Christopher A., and Tao Zha, 1998. "Bayesian Methods for Dynamic Multivariate Models," International Economic Review, 39(4), 949-68.

[64] Stock, James H., and Mark W. Watson, 2001. "Vector Autoregressions," Journal of Economic Perspectives, 15(4), 101-115.

[65] Stock, James H., and Mark W. Watson, 2002. "Macroeconomic Forecasting Using Diffusion Indexes," Journal of Business 8 Economic Statistics, 20 (2), 147-52.

[66] Stock, James H., and Mark W. Watson, 2005. "Implications of dynamic factor models for VAR analysis," NBER WP, 11467.

[67] Tille, Cédric, 2008. "Financial Integration and the Wealth Effect of Exchange Rate Fluctuations," Journal of International Economics, 75, 283-94.

[68] Uhlig, Harald, 2005. "What are the effects of monetary policy on output? Results from an agnostic identification procedure," Journal of Monetary Economics, 52, 381-419.

[69] Zurlinden, Mathias, 2005. "Credit in the monetary transmission mechanism: An overview of some recent research using Swiss data," Swiss National Bank Economic Studies,

2005-1. 


\section{Appendix}

\section{A. Stylized facts}

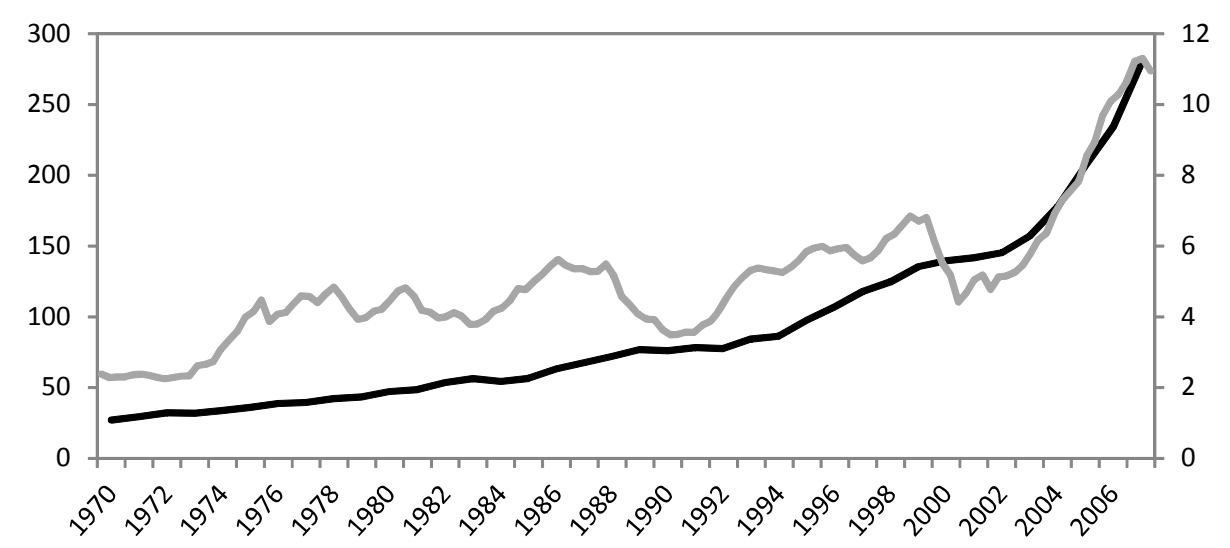

Sum of total foreign assets and liabilities (percent of GDP, LHS)

Sum of total foreign investment income receipts and payments (percent of GDP, RHS)

Figure A1: United States - Total foreign wealth and investment income Sources: Lane and Milesi-Ferretti (2007) and US Bureau of Economic Analysis.

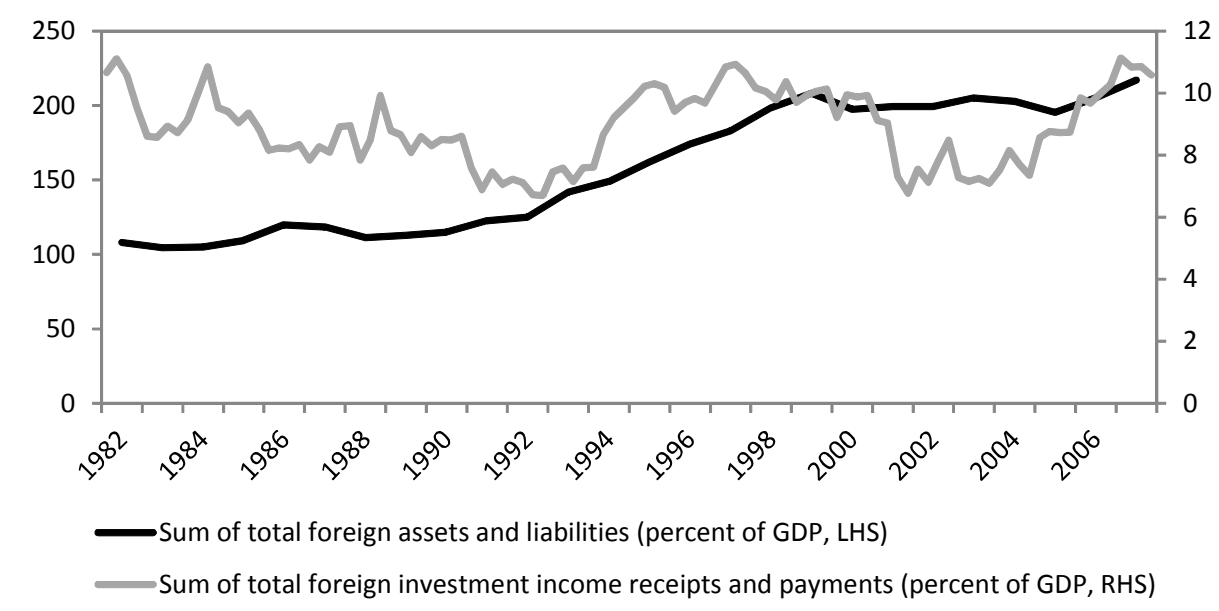

Figure A2: Canada - Total foreign wealth and investment income Sources: Lane and Milesi-Ferretti (2007) and Statistics Canada. 


\section{B. Data and specifications}

\begin{tabular}{|c|c|c|c|c|c|}
\hline Mnemonic & Description & Source & $\begin{array}{l}\text { Specification } \\
\text { (吕easonally a djusted/ } \\
\text { non addjusted) }\end{array}$ & $\begin{array}{l}\text { Prior } \\
\text { (random walk, } \\
\text { white noise) }\end{array}$ & $\begin{array}{l}\text { Identification } \\
\text { (slow/fast) }\end{array}$ \\
\hline$P$ & GDP deflator & $\begin{array}{l}\text { US Bureau of Economic } \\
\text { A nalysis (BEA) }\end{array}$ & $\log , \mathrm{sa}$ & $\mathrm{rw}$ & s \\
\hline CPI & Consumer Price index & $\begin{array}{l}\text { US Bureau of Labor } \\
\text { Statistics (BLS) }\end{array}$ & $\log$, sa & rw & s \\
\hline PPI & Producer price index & BLS & $\log$, sa & rw & s \\
\hline PCOM & Commodities price index & BLS & $\log , \mathrm{sa}$ & rw & s \\
\hline Y & GDP at constant prices & BEA & $\log$, sa & rw & s \\
\hline C & Personal consumption expenditures at constant prices & BEA & $\log$, sa & rw & s \\
\hline INV & Gross fixed capital formation at constant prices & OECD EO & $\log , \mathrm{sa}$ & rw & s \\
\hline G & Government consumption and investment at constant prices & BEA & $\log$, sa & rw & s \\
\hline D & Government debt & $\begin{array}{l}\text { US Department of the } \\
\text { Treasury }\end{array}$ & percent of GDP, sa & wn & s \\
\hline NX & Net exports & $\begin{array}{l}\text { BEA, Nominal GDP data } \\
\text { also from BEA }\end{array}$ & percent of GDP, sa & wn & s \\
\hline UR & Unemployment rate & BLS & percent, sa & rw & s \\
\hline Housing & New private housing units started & US Census Bureau & $\log$, sa & wn & s \\
\hline IP & Industrial production index & Federal Reserve, US & $\log$, sa & rw & s \\
\hline i & Federal funds rate & Federal Reserve, US & percent, na & rw & - \\
\hline $\mathrm{i} 10 \mathrm{Yr}$ & 10 year treasury benchmark bond yields & $\begin{array}{l}\text { US Department of the } \\
\text { Treasury }\end{array}$ & percent, na & rw & $f$ \\
\hline NEER & Nominal effective exchange rate & IMF IFS & $\log , \mathrm{sa}$ & rw & $f$ \\
\hline S\&P 500 & Stock market index & Standard \& Poor's & $\log$, na & rw & $f$ \\
\hline NBR & Nonborrowed reserves of depository institutions & Federal Reserve, US & $\log$, sa & rw & $f$ \\
\hline TR & Total reserves of depository institutions & Federal Reserve, US & $\log , \mathrm{sa}$ & rw & $f$ \\
\hline M2 & Money supply M2 & Federal Reserve, US & $\log , \mathrm{sa}$ & rw & $f$ \\
\hline FIrec & Real foreign investment income receipts & BEA & $\log$, sa & rw & $f$ \\
\hline FIpay & Real foreign investment income payments & BEA & $\log , \mathrm{sa}$ & rw & $f$ \\
\hline NFI & Foreign investment income balance & BEA & percent of GDP, sa & wn & $f$ \\
\hline FDIrec & Real foreign direct investment receipts & BEA & $\log , \mathrm{sa}$ & rw & $f$ \\
\hline FDIpay & Real foreign direct investment payments & BEA & $\log , \mathrm{sa}$ & rw & $f$ \\
\hline FGIrec & Real foreign government investment receipts & BEA & $\log , \mathrm{sa}$ & rw & $f$ \\
\hline FGIpay & Real foreign government investment payments & BEA & $\log , \mathrm{sa}$ & rw & $f$ \\
\hline FOIrec & Real foreign other investment receipts & BEA & $\log , \mathrm{sa}$ & rw & $f$ \\
\hline FOIpay & Real foreign other investment payments & BEA & $\log , \mathrm{sa}$ & rw & $f$ \\
\hline NFDI & Foreign direct investment income balance & BEA & percent of GDP, sa & wn & $f$ \\
\hline NFGI & Foreign government investment income balance & BEA & percent of GDP, sa & wn & $f$ \\
\hline NFOI & Foreign other investment income balance & BEA & percent of GDP, sa & wn & $\mathrm{f}$ \\
\hline
\end{tabular}

Table B1: Dataset United States 


\begin{tabular}{|c|c|c|c|c|c|}
\hline$P$ & GDP deflator & Statistics Canada & log, sa & rw & $\mathrm{s}$ \\
\hline CPI & Consumer price index & Statistics Canada & $\log$, sa & rw & s \\
\hline PPI & Producer price index & IMF IFS & $\log$, sa & rw & $\mathrm{s}$ \\
\hline COMPI & Commodities price index & Bank of Canada & $\log$, sa & rw & s \\
\hline Y & GDP at constant prices & Statistics Canada & $\log$, sa & rw & $s$ \\
\hline C & Final consumption expenditures at constant prices & Statistics Canada & $\log$, sa & rw & \\
\hline INV & Gross fixed capital formation at constant prices & Statistics Canada & $\log$, sa & rw & s \\
\hline G & Government net current expenditures & Statistics Canada & $\log$, sa & rw & $s$ \\
\hline NX & Net exports & $\begin{array}{l}\text { Statistics Canada, } \\
\text { Nominal GDP data also from } \\
\text { Statistics Canada }\end{array}$ & percent of GDP, sa & wn & $\mathrm{s}$ \\
\hline UR & Unemployment rate & Statistics Canada & percent, sa & rw & $s$ \\
\hline Housing & Number of housing starts & $\begin{array}{l}\text { Canada Mortgage and Housing } \\
\text { Corporation }\end{array}$ & $\log$, sa & wn & s \\
\hline IP & Industrial production index & The Conference Board & $\log , \mathrm{sa}$ & rw & $\mathrm{s}$ \\
\hline$i^{*}$ & US federal funds rate & Federal Reserve, US & percent, na & rw & s \\
\hline i & Overnight money market rate & IMF IFS & percent, na & rw & - \\
\hline $\mathrm{i} 10 \mathrm{Yr}$ & Government bond yields over 10 years & Statistics Canada & percent, na & rw & $f$ \\
\hline NEER & Nominal effective exchange rate & IMF IFS & $\log$, sa & rw & $f$ \\
\hline S\&P/TSX 60 & Stock market index & Standard and Poor's & $\log , \mathrm{na}$ & rw & $f$ \\
\hline MO & Money supply MO & Statistics Canada & $\log$, sa & rw & $f$ \\
\hline M2 & Money supply M2 & Statistics Canada & $\log$, sa & rw & $f$ \\
\hline FIrec & Real foreign investment income receipts & Statistics Canada & $\log$, sa & rw & $f$ \\
\hline FIpay & Real foreign investment income payments & Statistics Canada & $\log$, sa & rw & $f$ \\
\hline NFI & Foreign investment income balance & Statistics Canada & $\log$, sa & wn & $f$ \\
\hline FDIrec & Real foreign direct investment receipts & Statistics Canada & $\log$, sa & $\mathrm{rw}$ & $f$ \\
\hline FDIpay & Real foreign direct investment payments & Statistics Canada & $\log$, sa & rw & $f$ \\
\hline FPIrec & Real foreign portfolio investment receipts & Statistics Canada & $\log$, sa & rw & $f$ \\
\hline FPIpay & Real foreign portfolio investment payments & Statistics Canada & $\log$, sa & rw & $f$ \\
\hline FOIrec & Real foreign other investment receipts & Statistics Canada & $\log$, sa & rw & $f$ \\
\hline F0Ipay & Real foreign other investment payments & Statistics Canada & $\log$, sa & rw & $f$ \\
\hline NFDI & Foreign direct investment income balance & Statistics Canada & percent of GDP, sa & wn & $f$ \\
\hline NFPI & Foreign portfolio investment income balance & Statistics Canada & percent of GDP, sa & wn & $f$ \\
\hline NFOI & Foreign other investment income balance & Statistics Canada & percent of GDP, sa & wn & $f$ \\
\hline
\end{tabular}

Table B2: Dataset Canada 


\section{Baseline estimations}
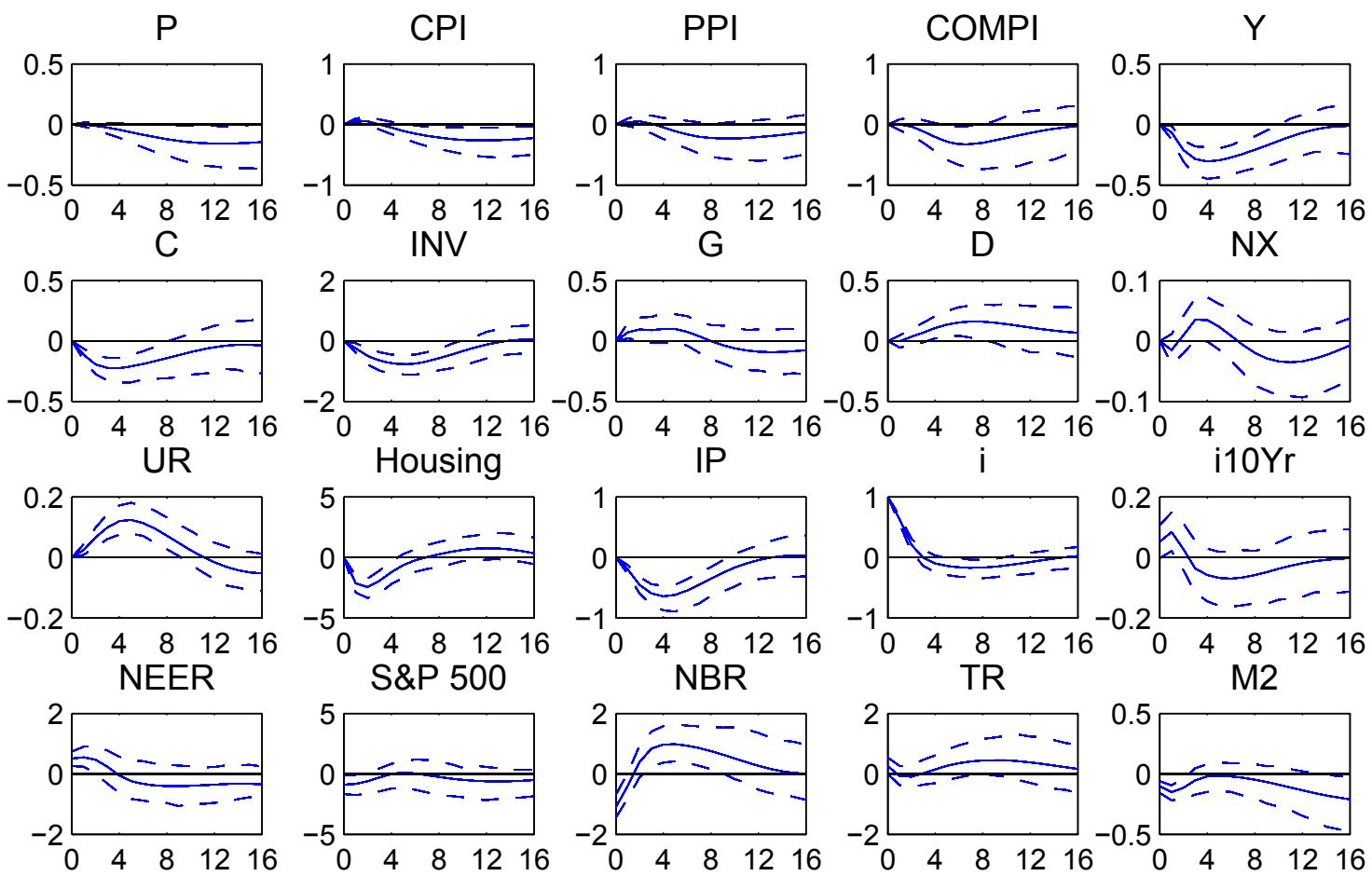

FIrec
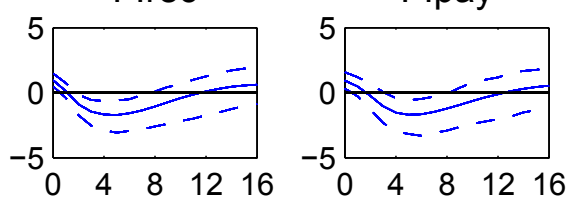

Figure C1: United States - Specification with total gross foreign investment income flows

Notes: The figure reports impulse response functions to a positive 100 basis points monetary policy shock in percentage points at the median 

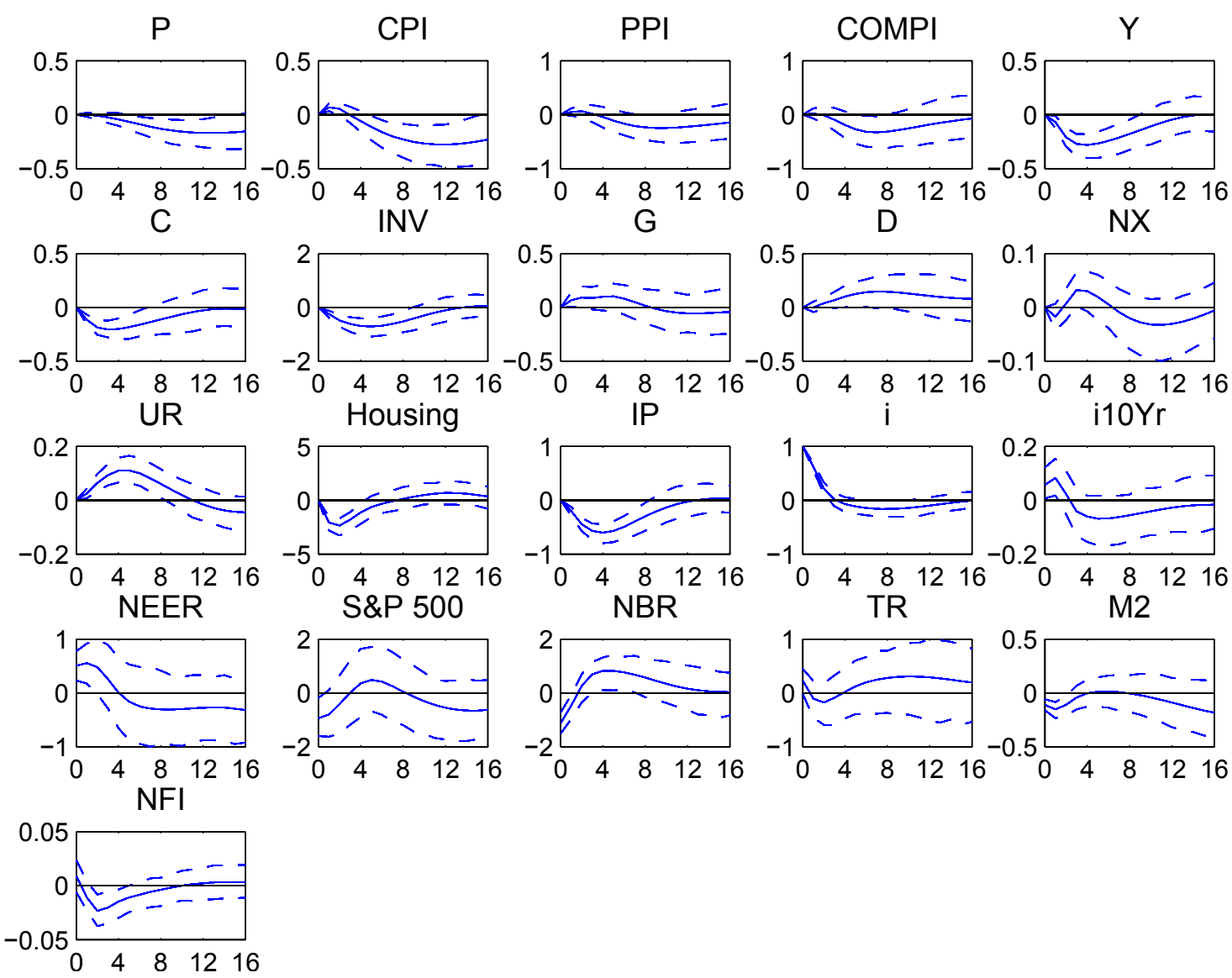

Figure C2: United States - Specification with total net foreign investment income flows Notes: The figure reports impulse response functions to a positive 100 basis points monetary policy shock in percentage points at the median 

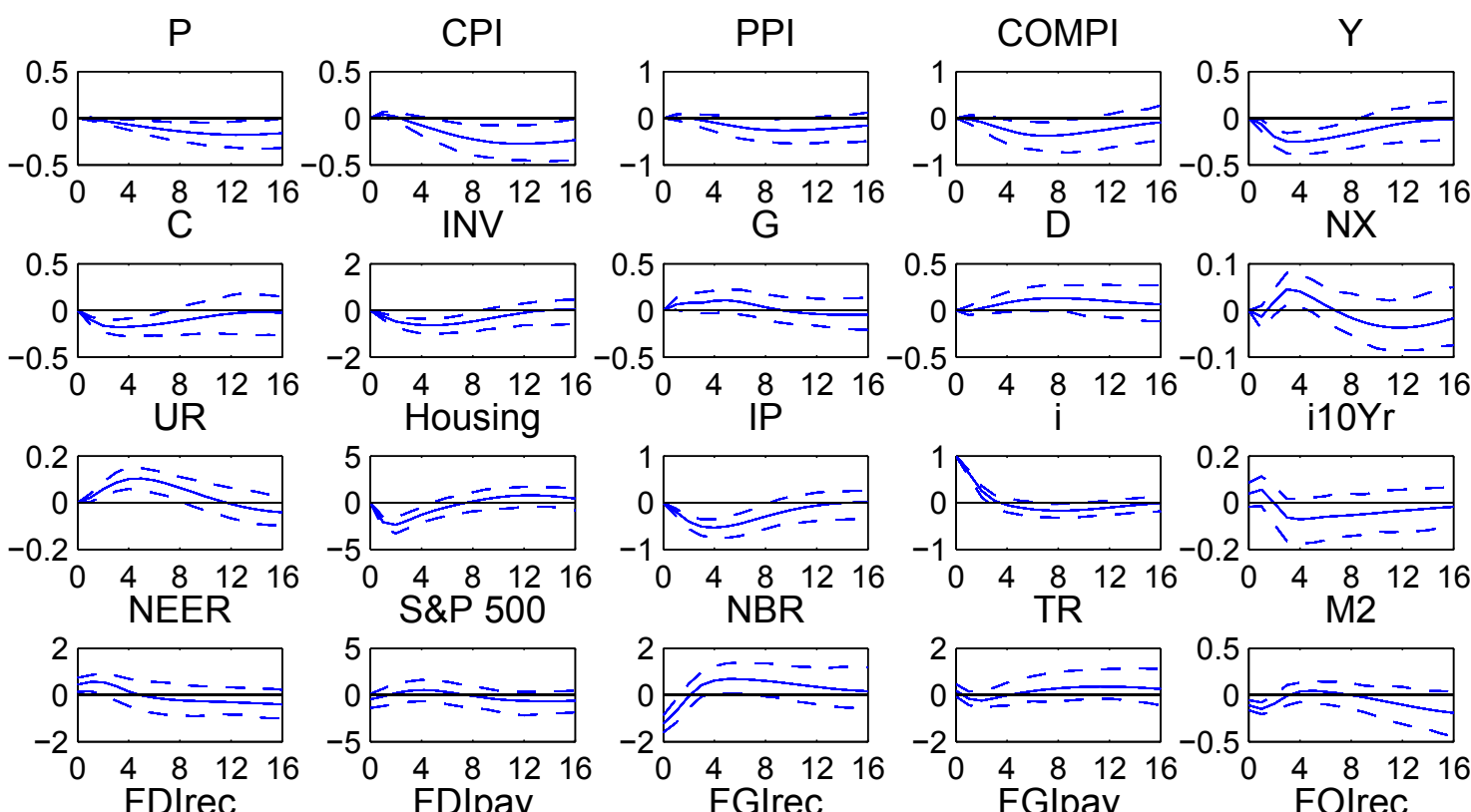

NBR

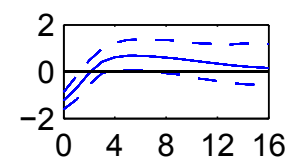

$\mathrm{TR}$

$\mathrm{M} 2$

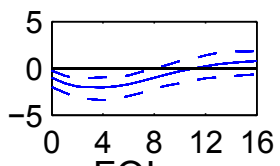
FDlpay
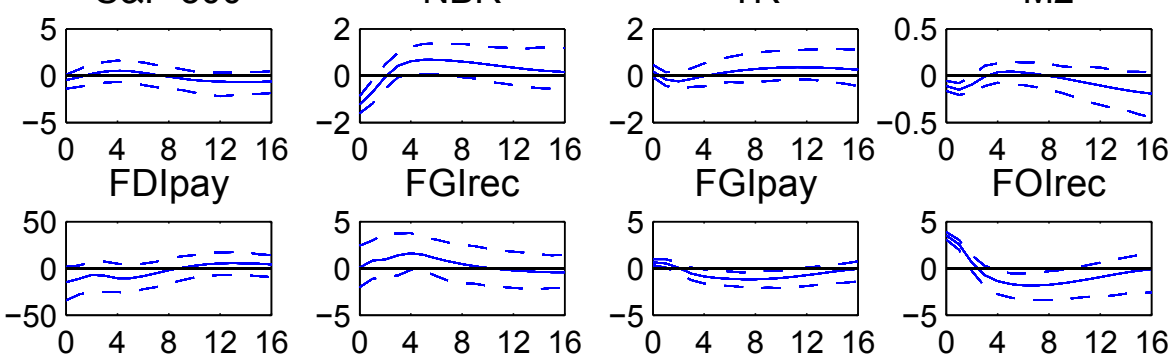
FGIrec
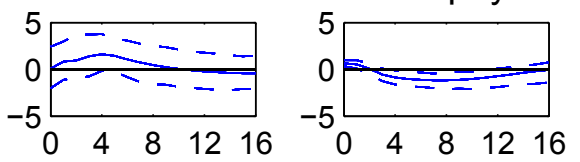
FOlrec
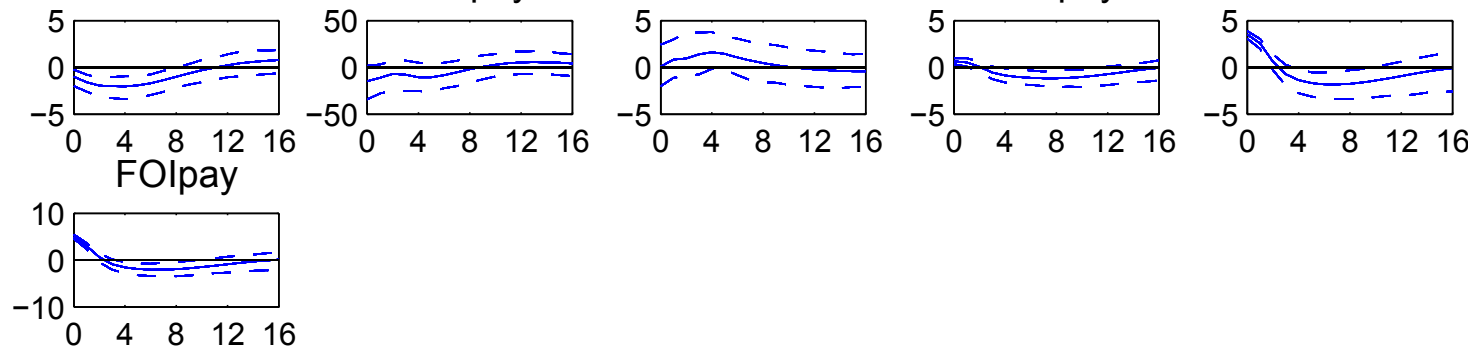

Figure C3: United States - Specification with decomposed gross foreign investment inc. flows

Notes: The figure reports impulse response functions to a positive 100 basis points monetary policy shock in percentage points at the median (solid line) and the 16 th and 84 th percentiles (dashed lines) of the distribution. 

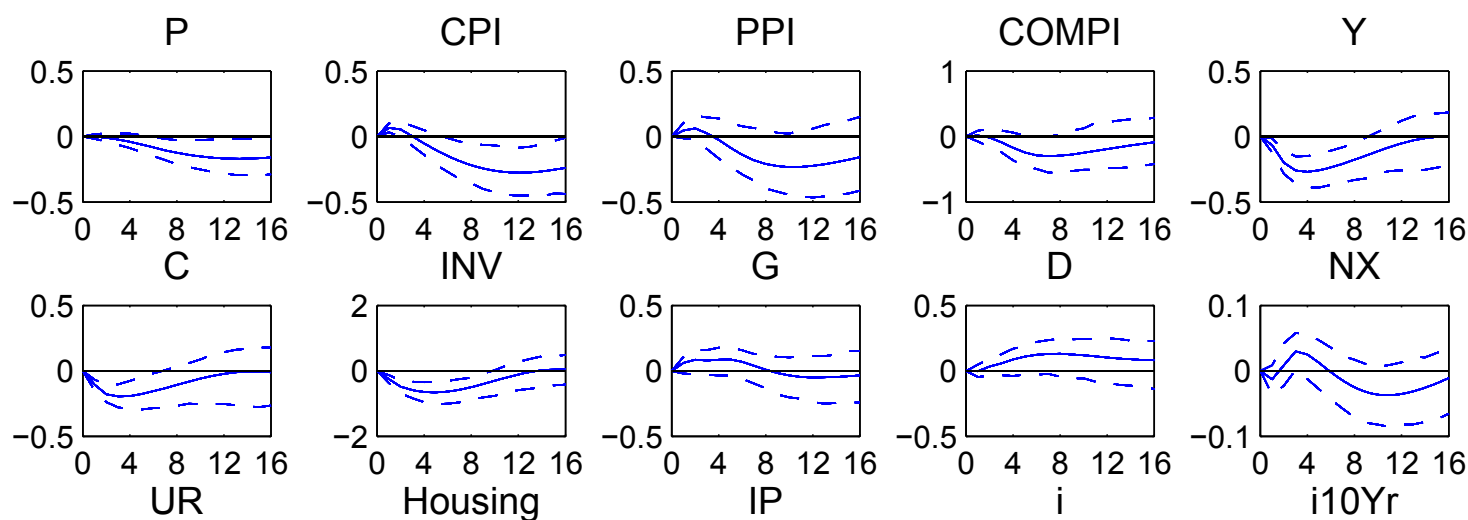

NX
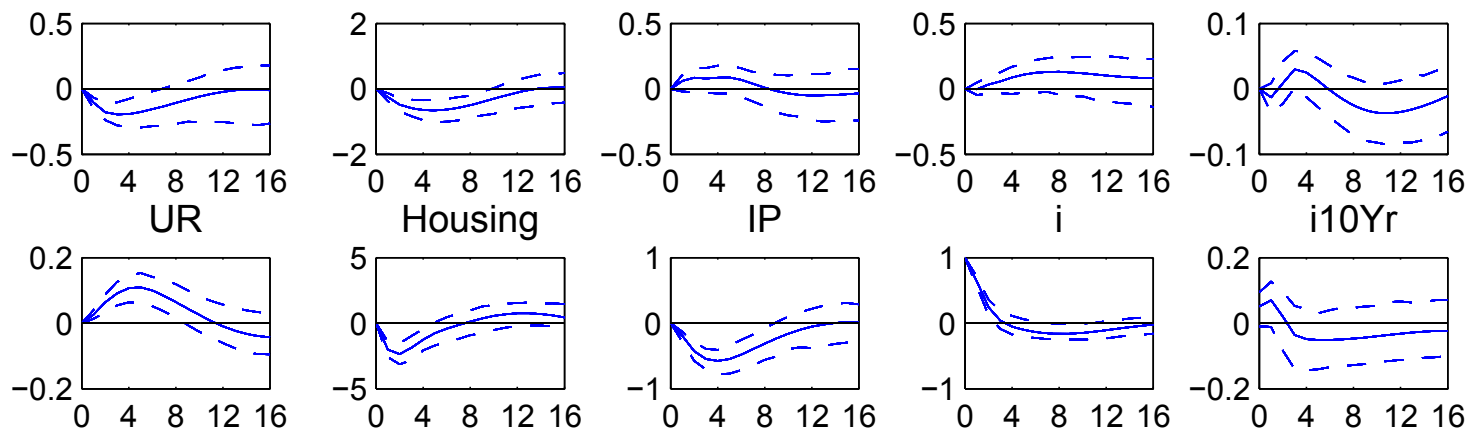

NEER
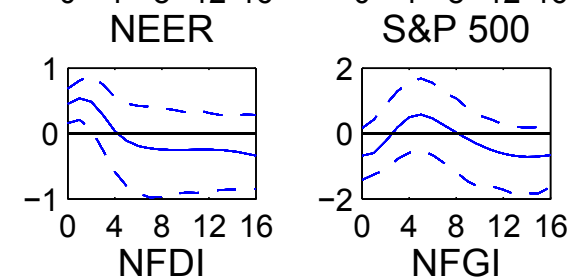

NBR
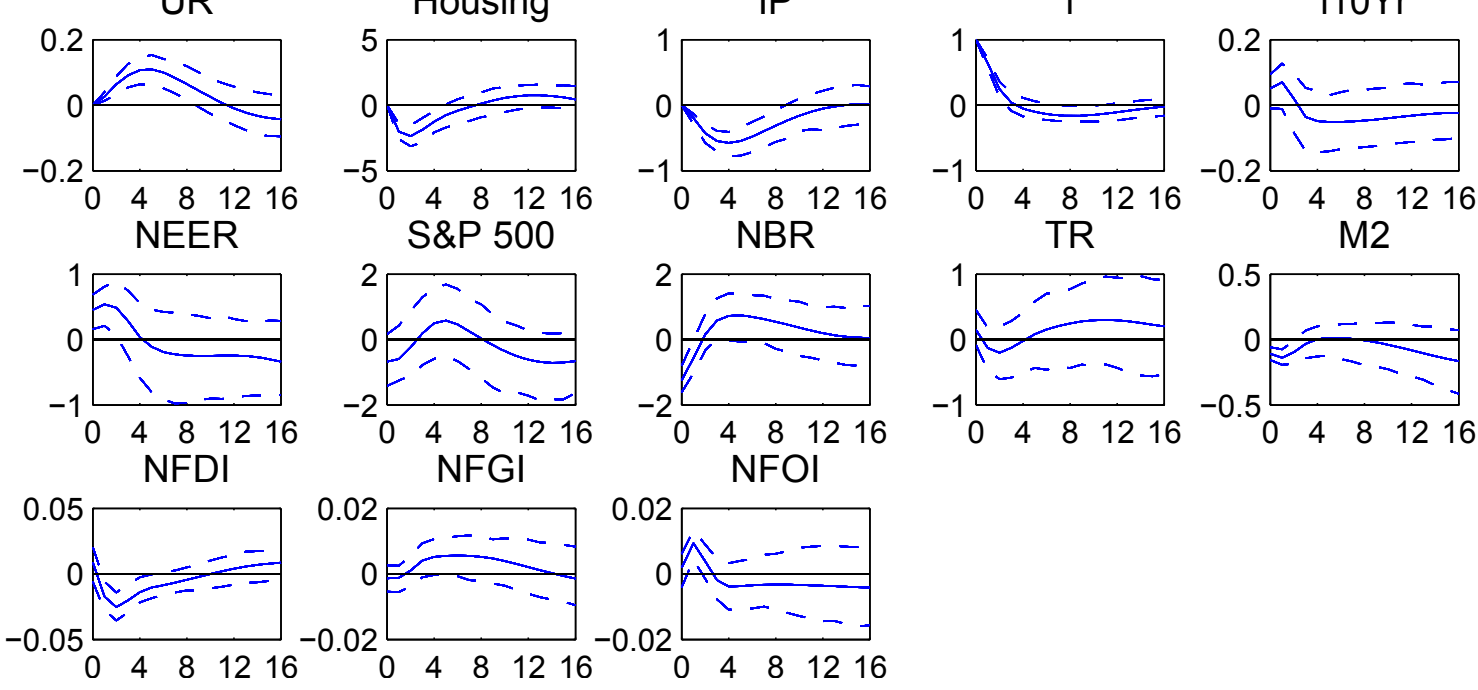

Figure C4: United States - Specification with decomposed net foreign investment inc. flows 

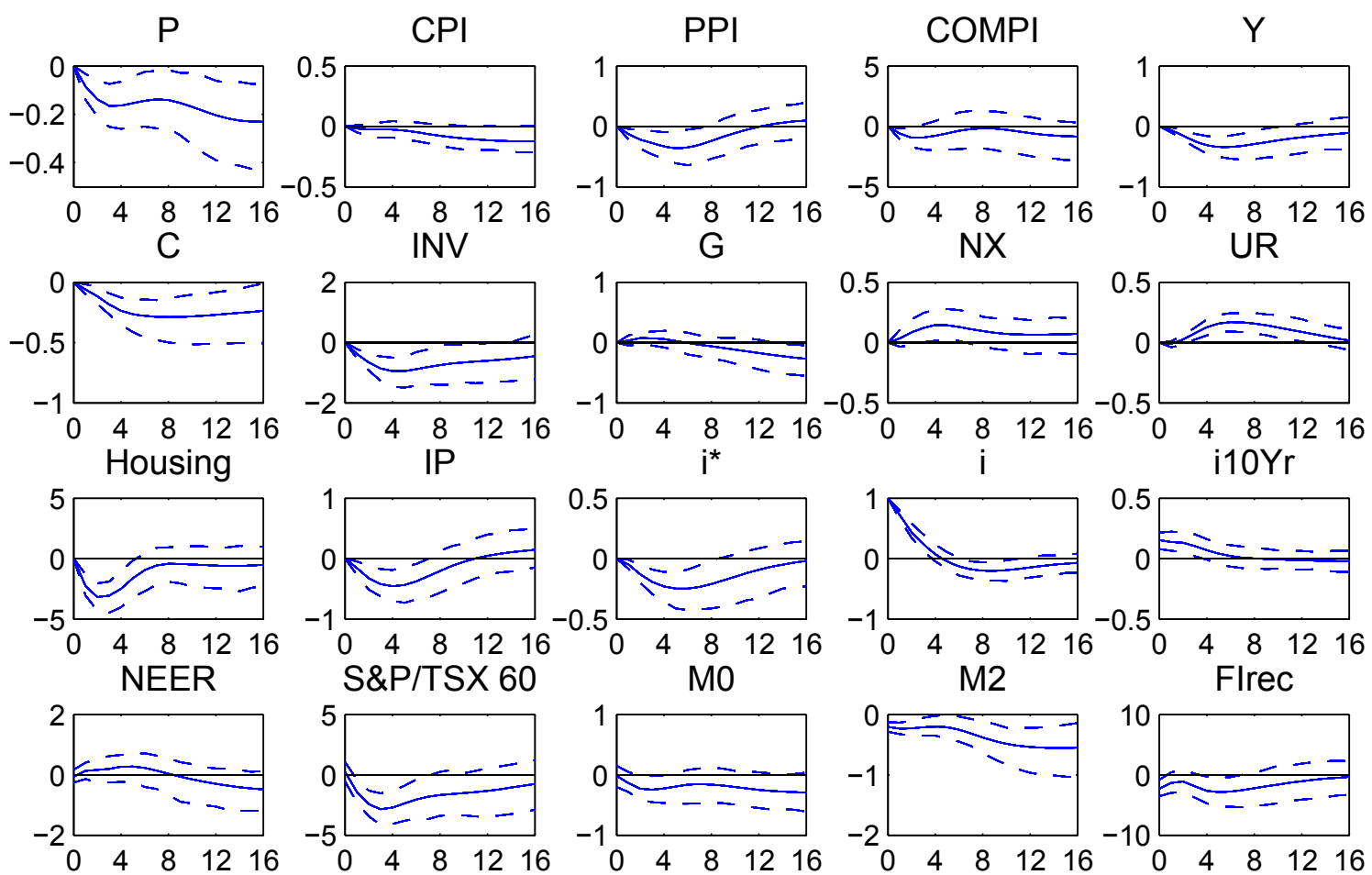

FIrec

Flpay

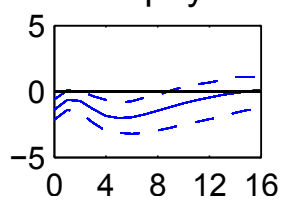

Figure C5: Canada - Specification with total gross foreign investment income flows 

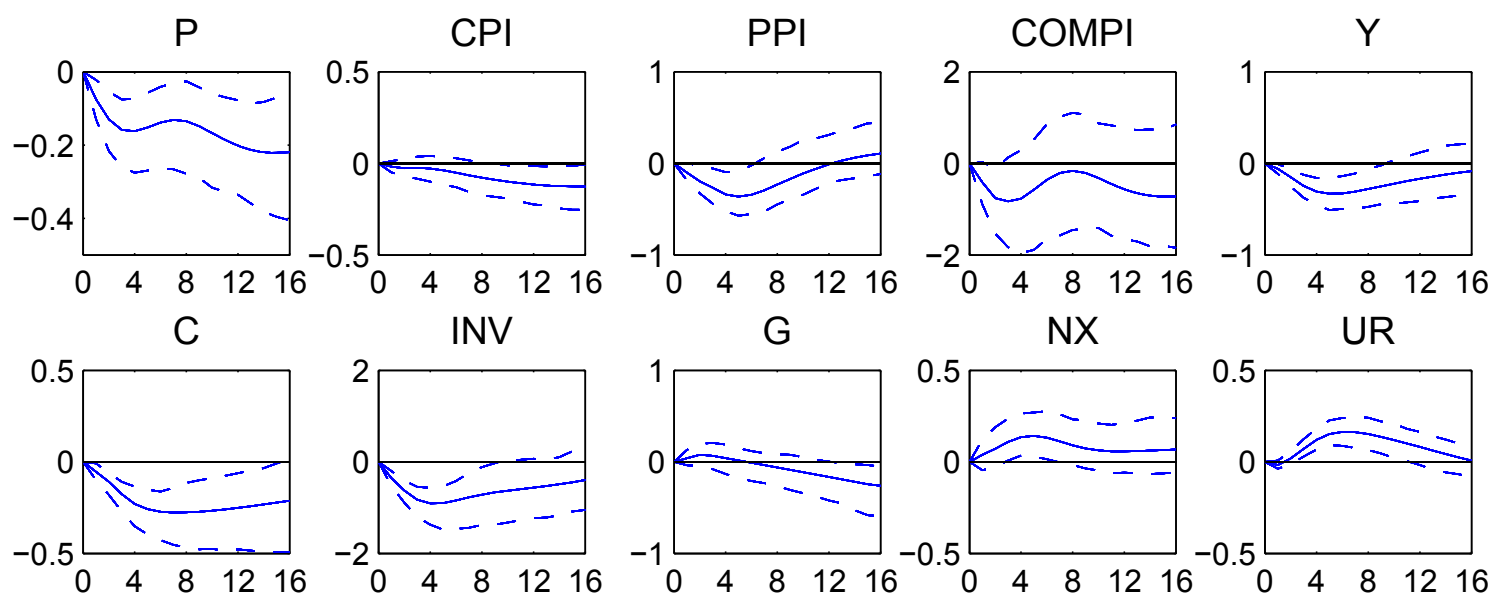

Housing

IP

$i^{*}$

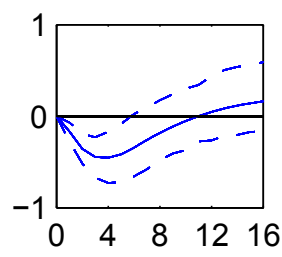

S\&P/TSX 60

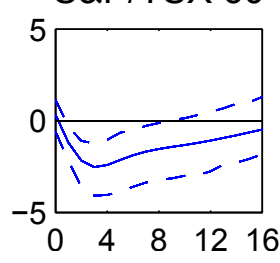

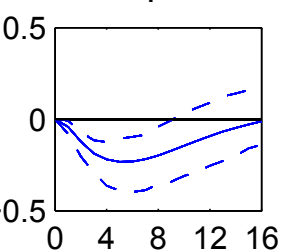

$\mathrm{MO}$

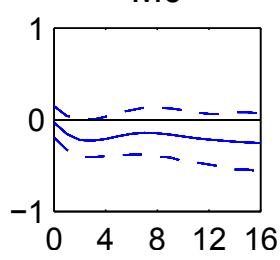

i10Yr

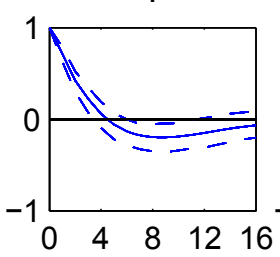

M2

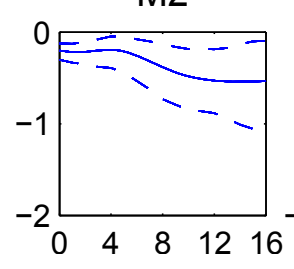

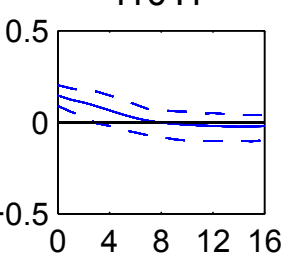

NFI

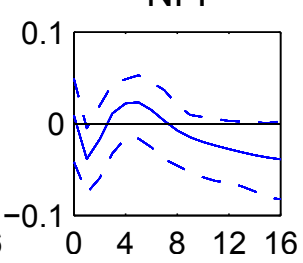

Figure C6: Canada - Specification with total net foreign investment income flows 

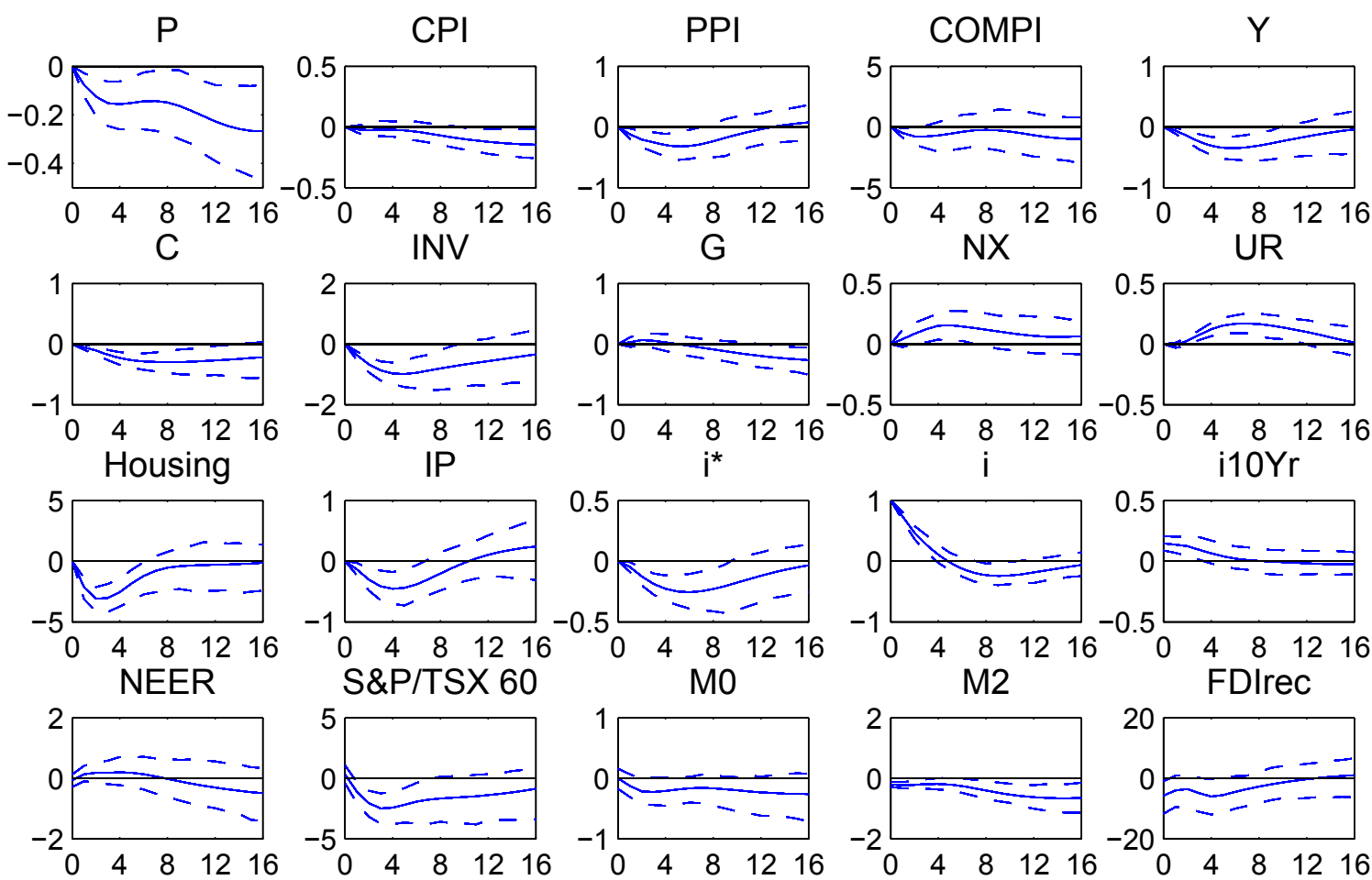

M0

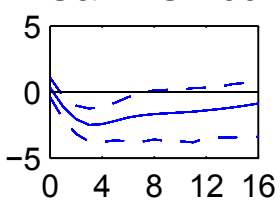

FDlpay
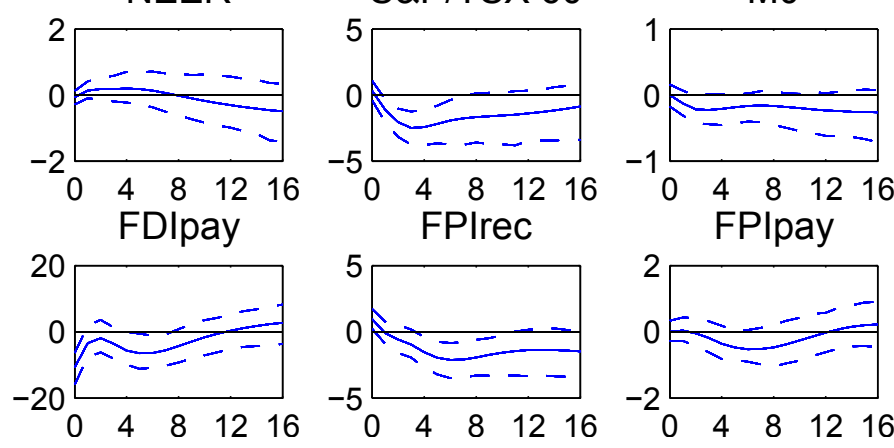

$\mathrm{M} 2$

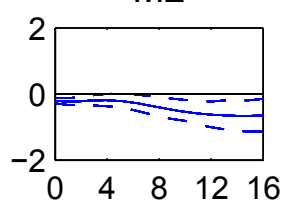

FDIrec
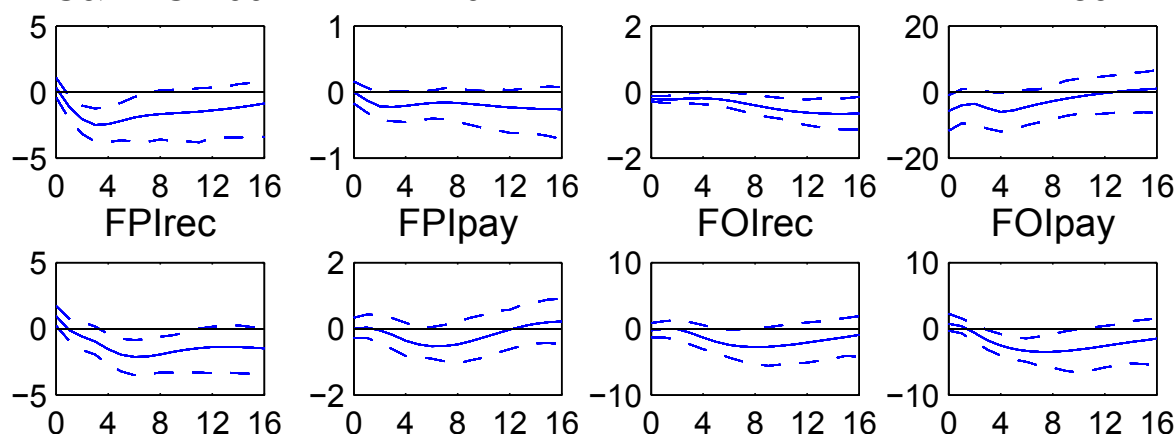

FOlpay

Figure C7: Canada - Specification with decomposed gross foreign investment income flows 

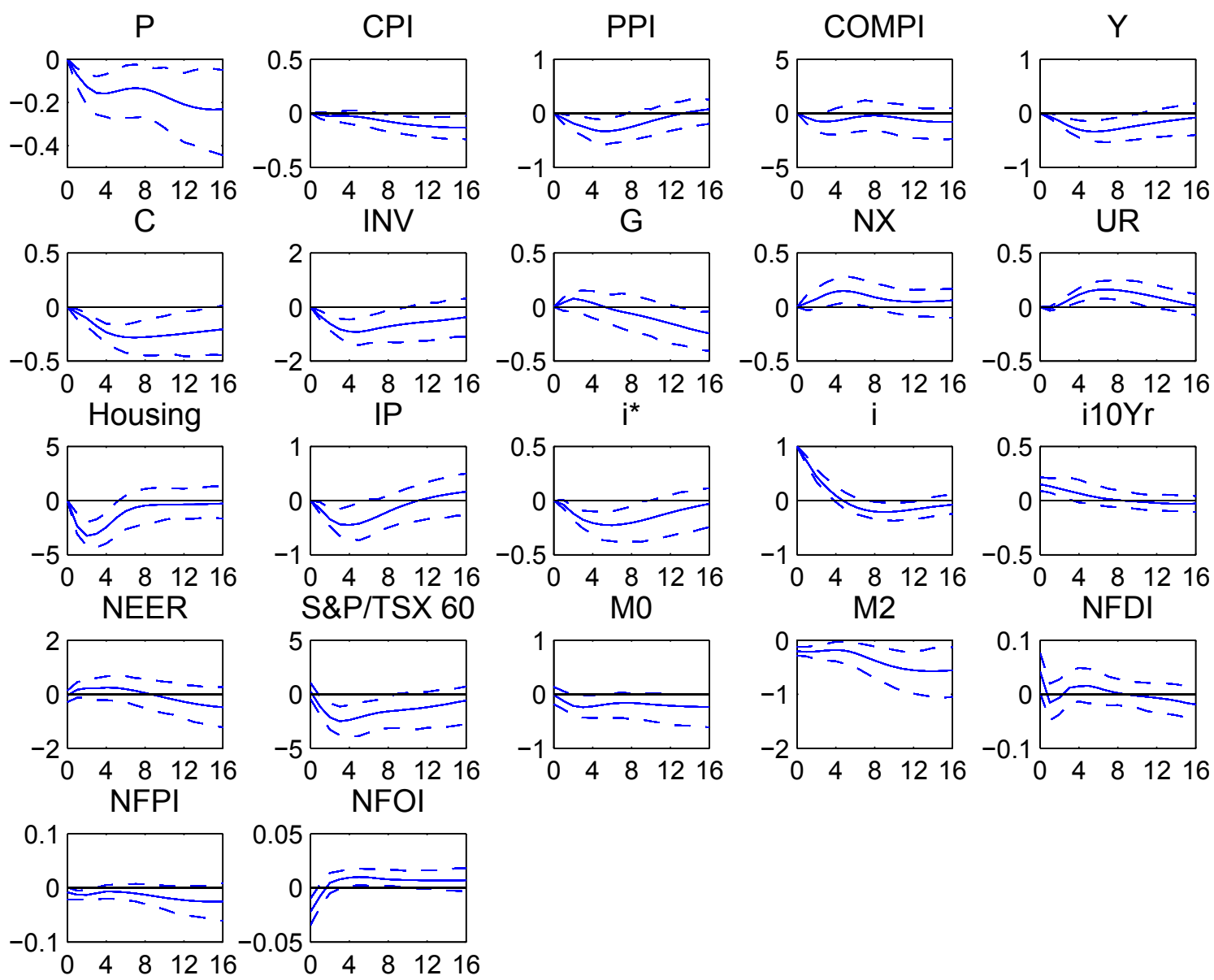

Figure C8: Canada - Specification with decomposed net foreign investment income flows Notes: The figure reports impulse response functions to a positive 100 basis points monetary policy shock in percentage points at the median 


\section{Comparison with small-scale VARs}

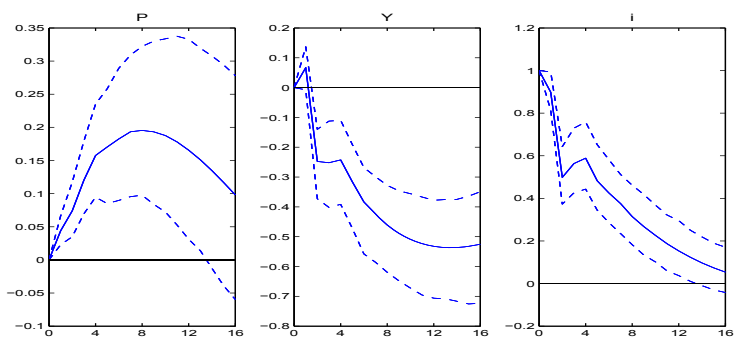

Figure D1: United States - Small specification 1

Notes: The figure reports impulse response functions to a positive 100 basis points monetary policy shock in percentage points at the median (solid line) and the 16th and 84th percentiles (dashed lines) of the distribution.
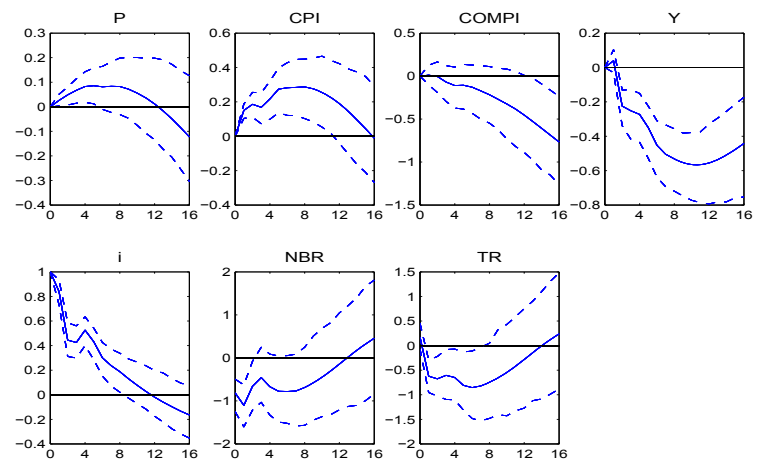

Figure D2: United States - Small specification 2

Notes: The figure reports impulse response functions to a positive 100 basis points monetary policy shock in percentage points at the median (solid line) and the 16th and 84 th percentiles (dashed lines) of the distribution. 

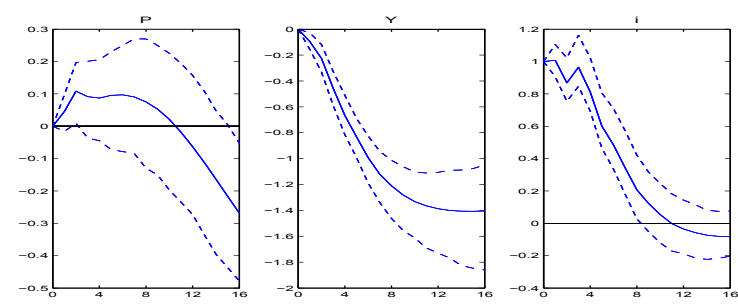

Figure D3: Canada - Small specification 1

Notes: The figure reports impulse response functions to a positive 100 basis points monetary policy shock in percentage points at the median (solid line) and the 16 th and 84 th percentiles (dashed lines) of the distribution.
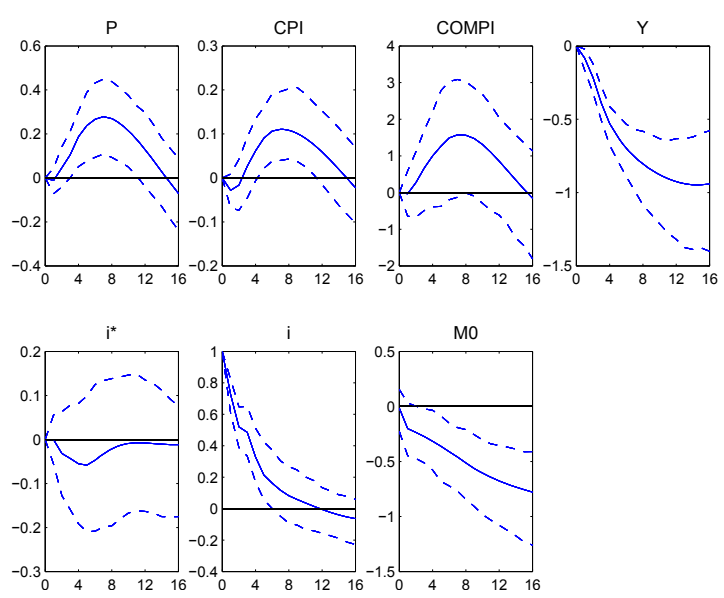

Figure D4: Canada - Small specification 2

Notes: The figure reports impulse response functions to a positive 100 basis points monetary policy shock in percentage points at the median (solid line) and the 16 th and 84 th percentiles (dashed lines) of the distribution. 


\section{E. Robustness checks}
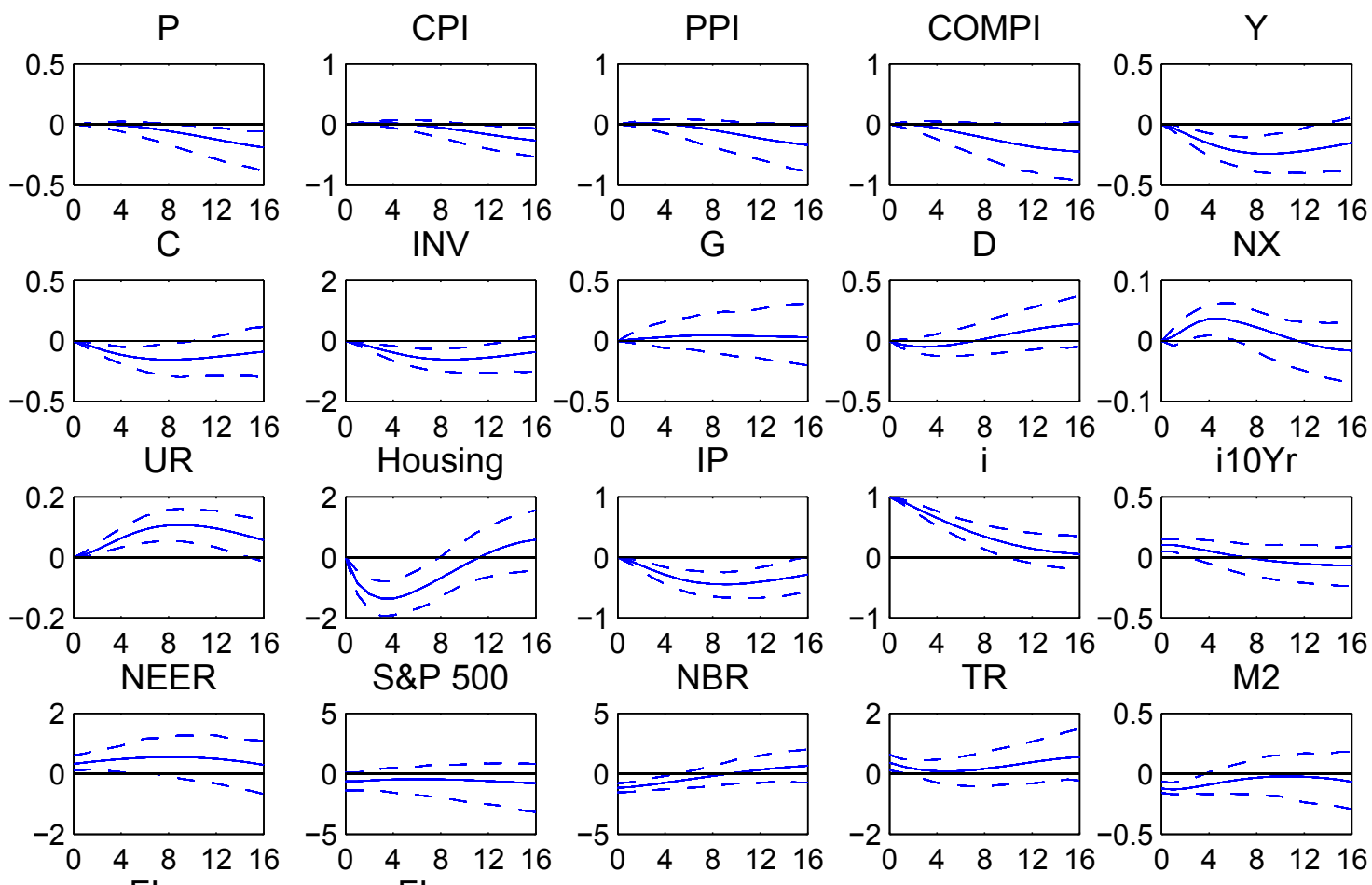

Flrec
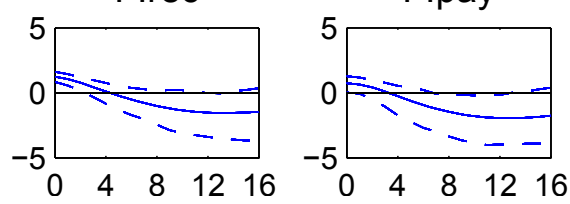

Figure E1: United States - Specification with total gross foreign investment income flows

Notes: The figure reports impulse response functions to a positive 100 basispoints monetary policy shock in percentage points at the median (solid line) and the 16 th and 84 th percentiles (dashed lines) of the distribution.. In contrast to the baseline estimations above, the shrinkage 

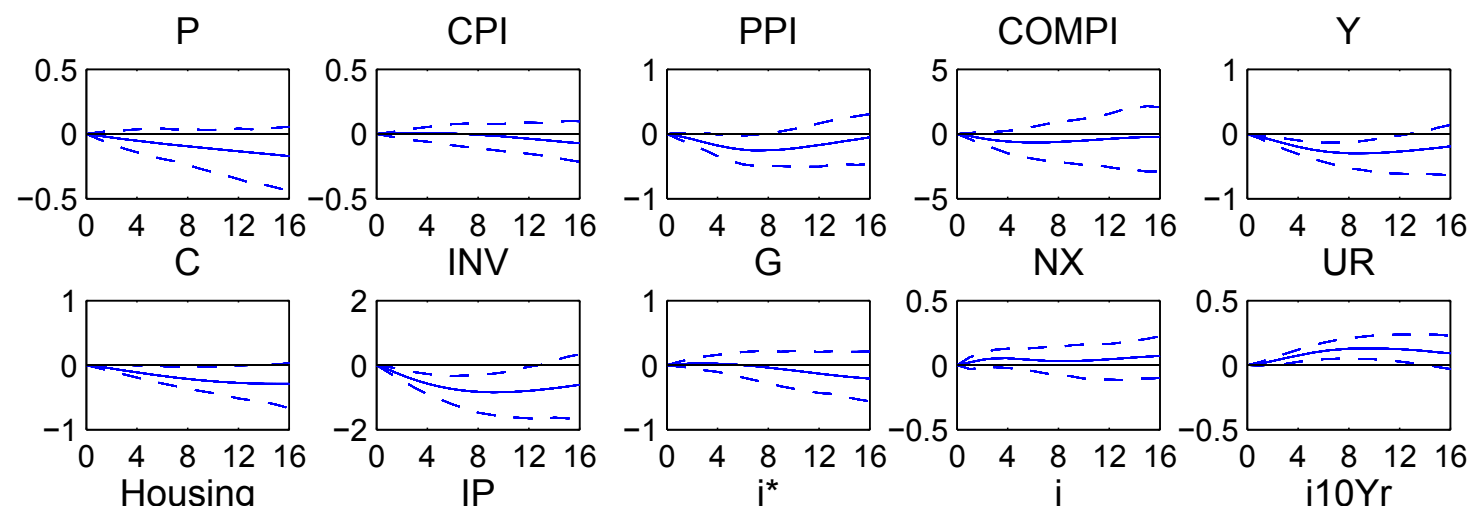

Housing
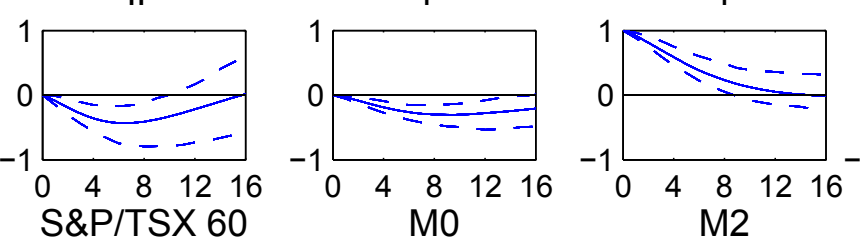

$\mathrm{i} 10 \mathrm{Yr}$
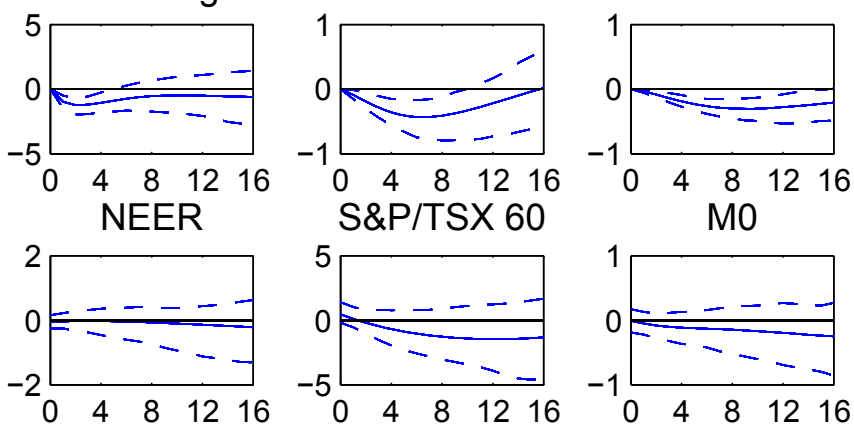

M2
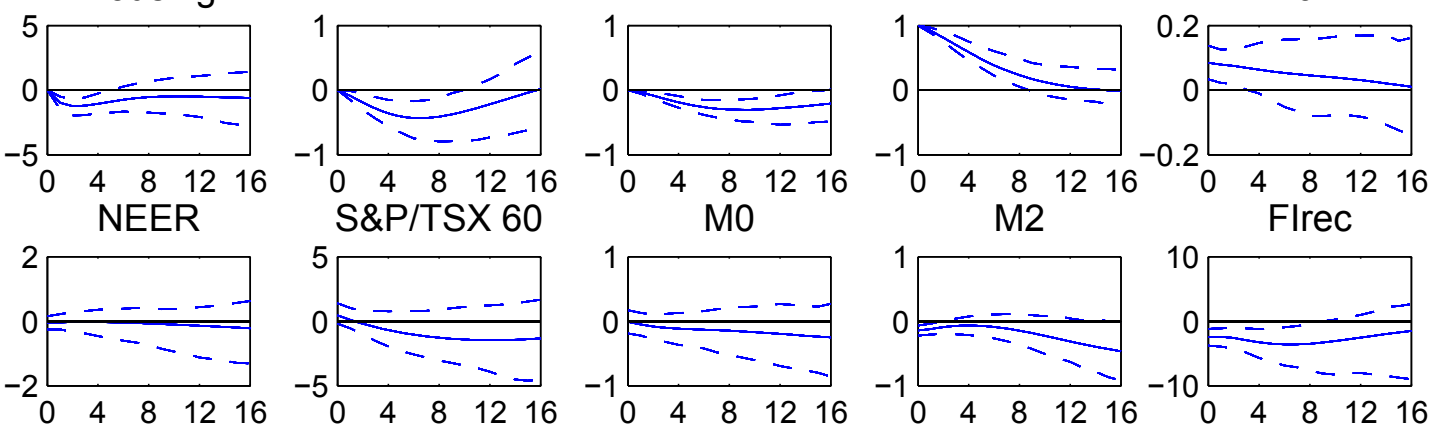

Flpay
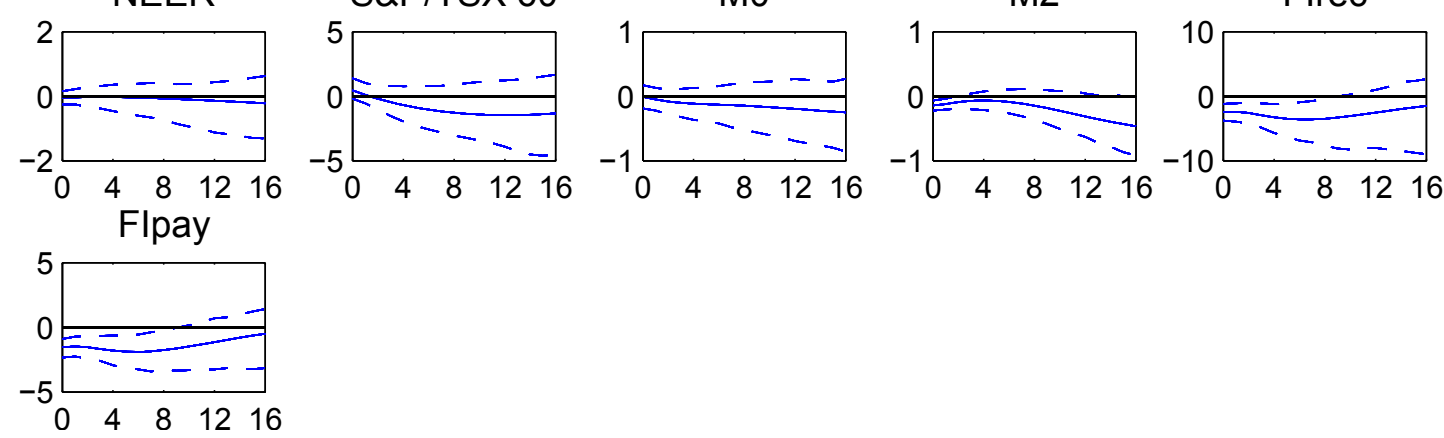

Figure E2: Canada - Specification with total gross foreign investment income flows

Notes: The figure reports impulse response functions to a positive 100 basis points monetary policy shock in percentage points at the median (solid line) and the 16 th and 84 th percentiles (dashed lines) of the distribution. In contrast to the baseline estimations above, the shrinkage parameter is chosen to match the fit of a small three-variable specification estimated by OLS. 

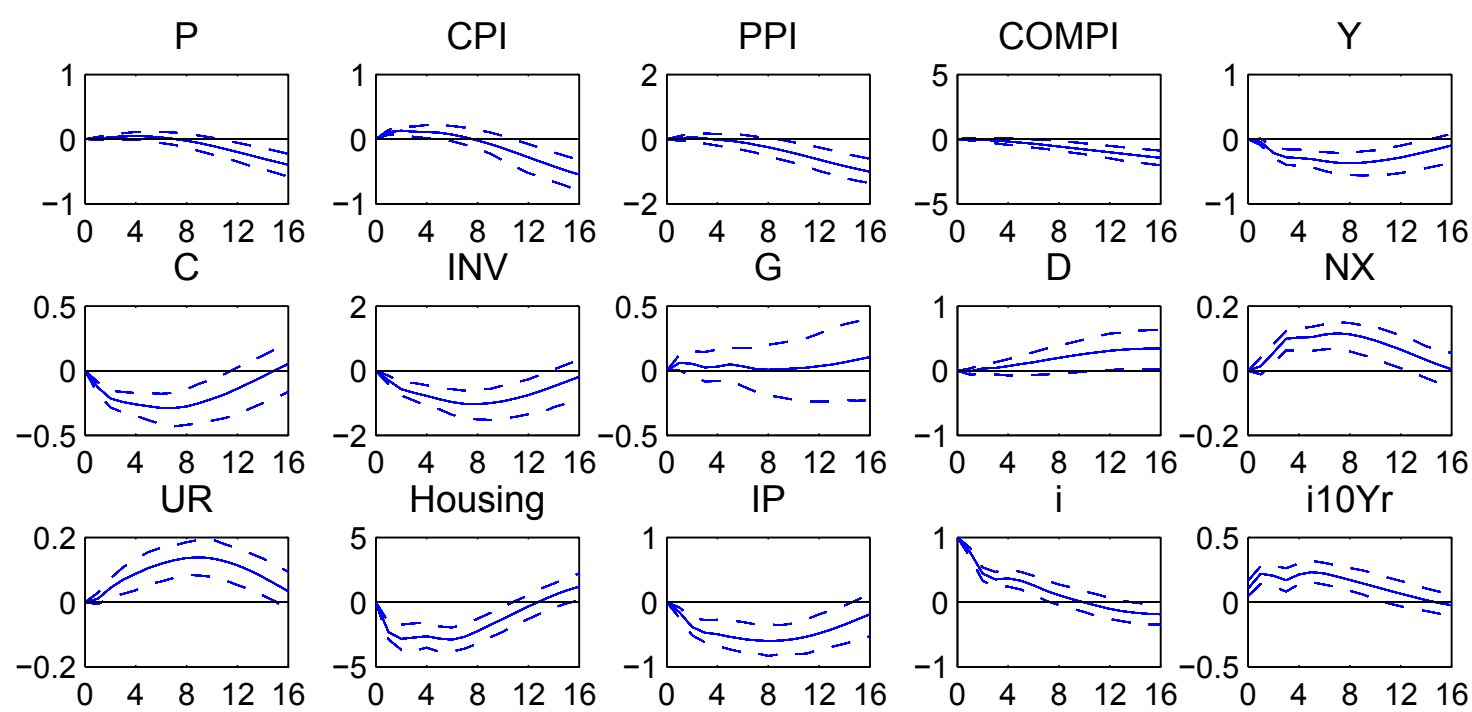

Housing
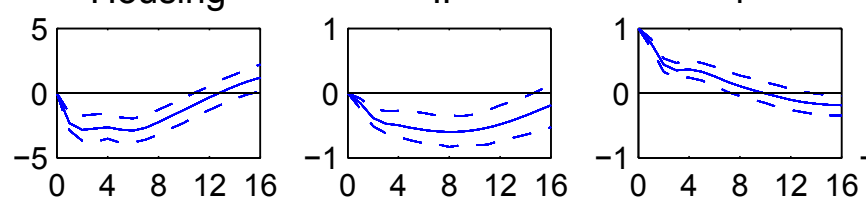

i10Yr

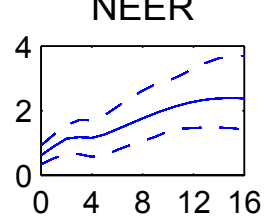

S\&P 500

NBR
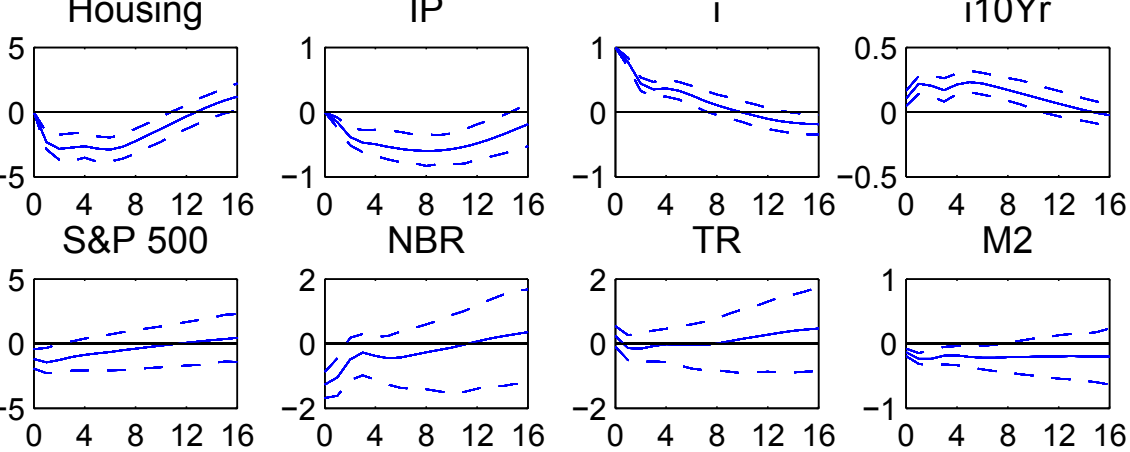

TR

$\mathrm{M} 2$

FIrec

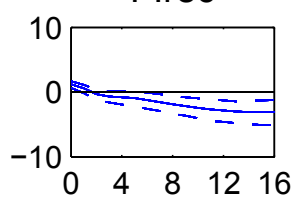

Flpay
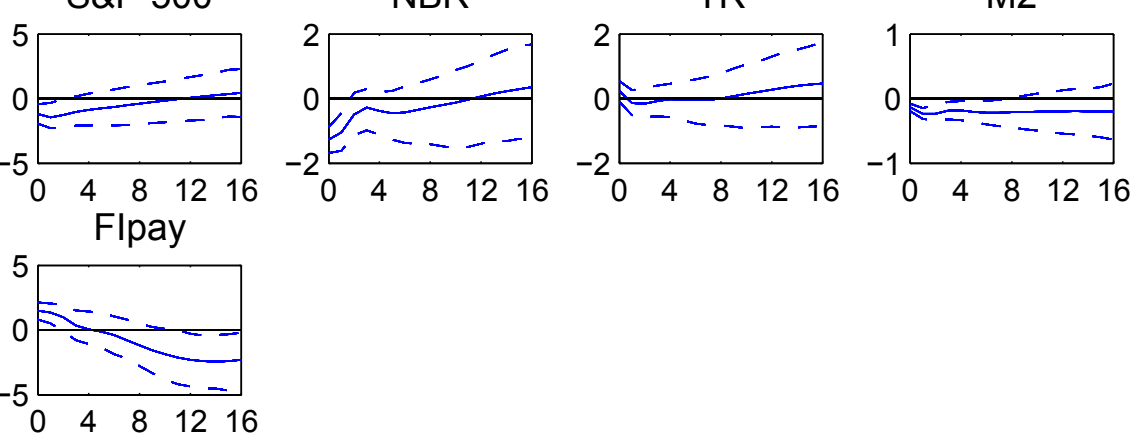

Figure E3: United States - Specification with total gross foreign investment income flows

Notes: The figure reports impulse response functions to a positive 100 basis points monetary policy shock in percentage points at the median (solid line) and the 16 th and 84 th percentiles (dashed lines) of the distribution. In contrast to the baseline estimations above, a prior on the sum of coefficients with $\tau=10 \lambda$ has been added. 

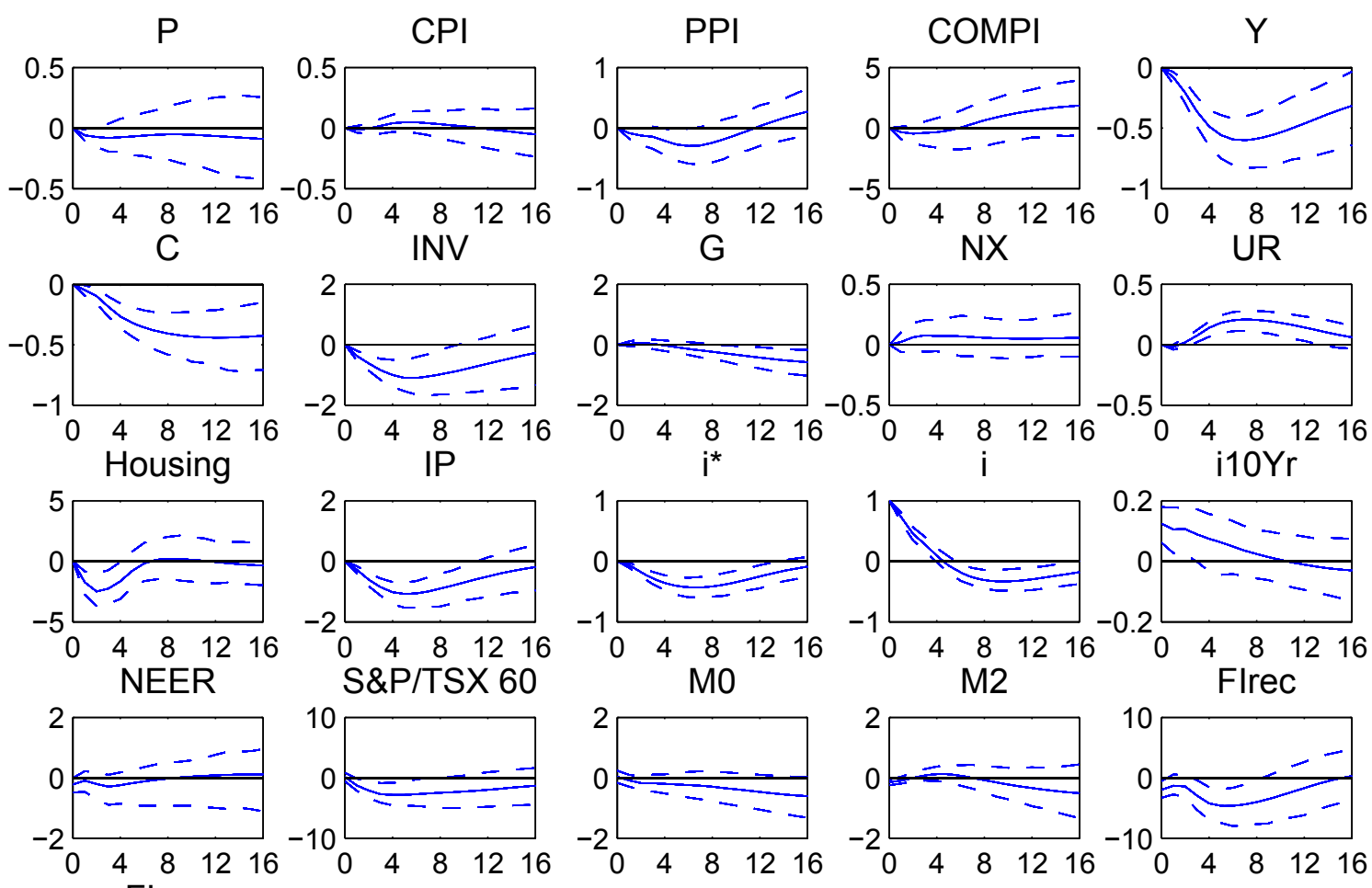

Flpay

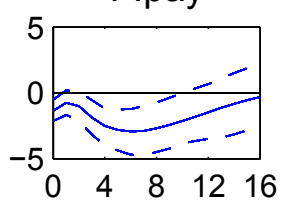

Figure E4: Canada - Specification with total gross foreign investment income flows

Notes: The figure reports impulse response functions to a positive 100 basis points monetary policy shock in percentage points at the median (solid line) and the 16 th and 84 th percentiles (dashed lines) of the distribution. In contrast to the baseline estimations above, a prior on the sum of coefficients with $\tau=10 \lambda$ has been added. 

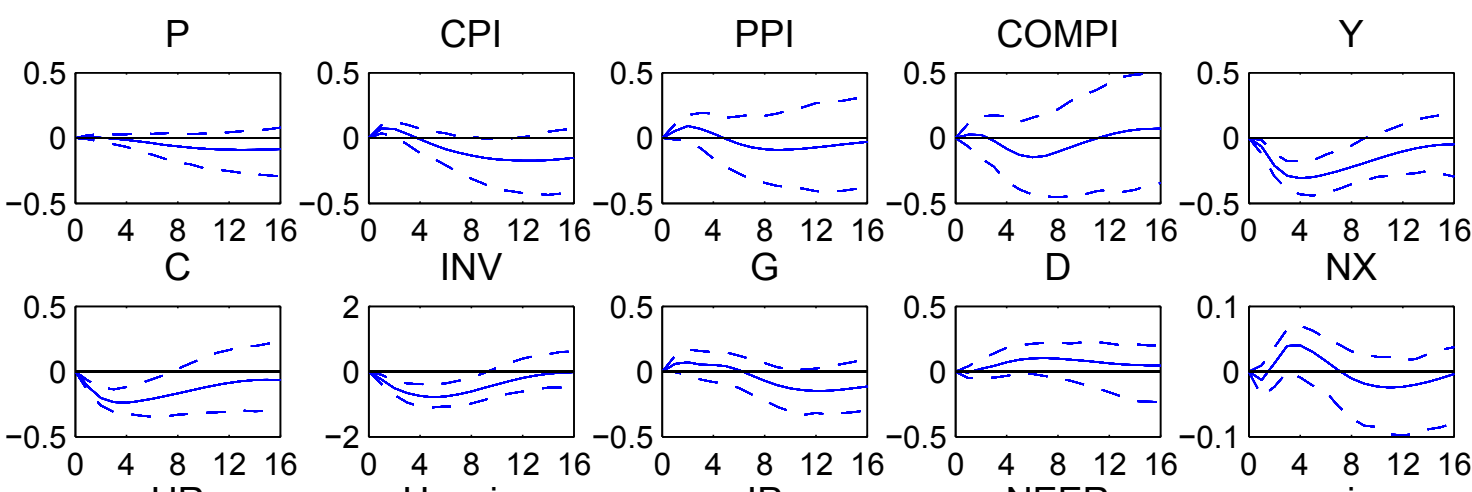

$\mathrm{D}$

$\mathrm{NX}$ UR

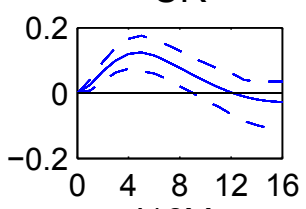

Housing
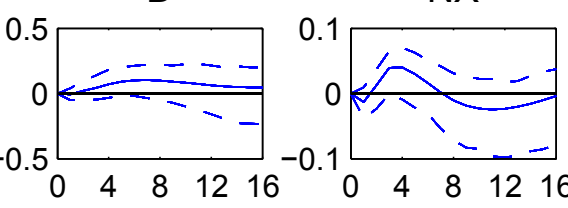

NEER
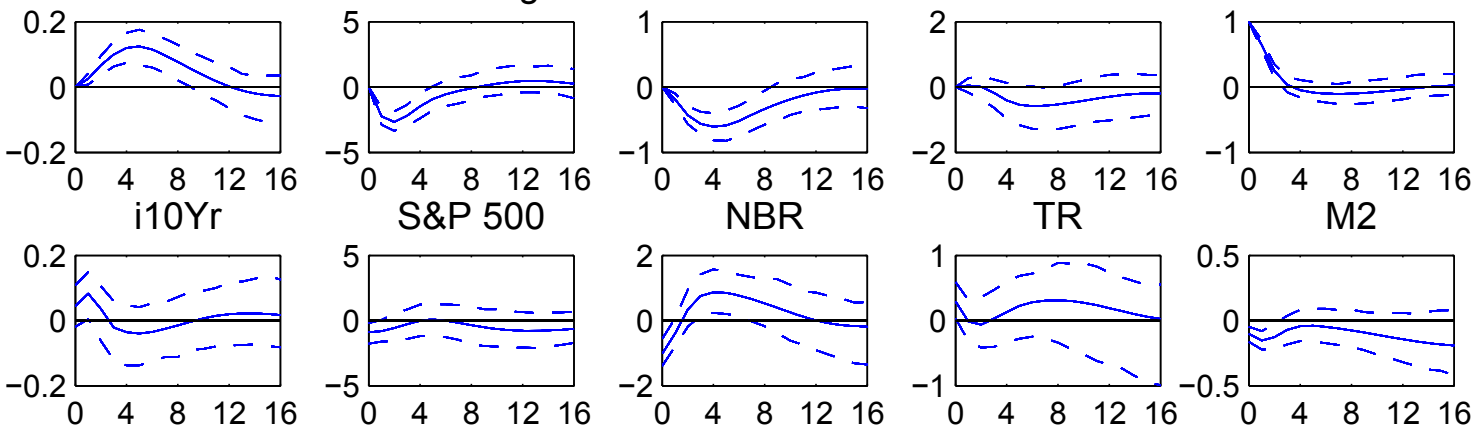

Flrec

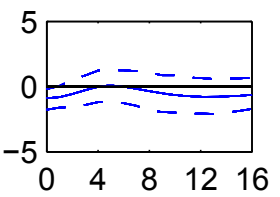

NBR

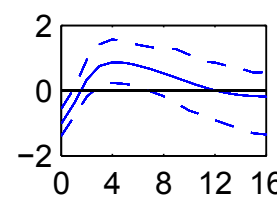

TR

$\mathrm{M} 2$

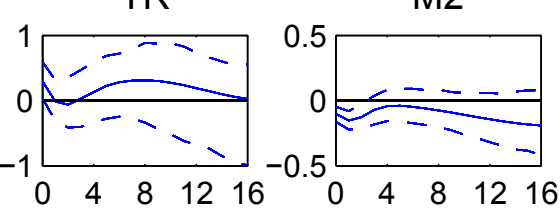

Flpay
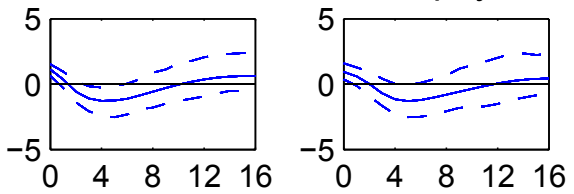

Figure E5: United States - Specification with total gross foreign investment income flows Notes: The figure reports impulse response functions to a positive 100 basis points monetary policy shock in percentage points at the median (solid line) and the 16 th and 84 th percentiles (dashed lines) of the distribution. In contrast to the baseline estimations above, the nominal effective exchange rate is assumed to be slow instead of fast moving. 

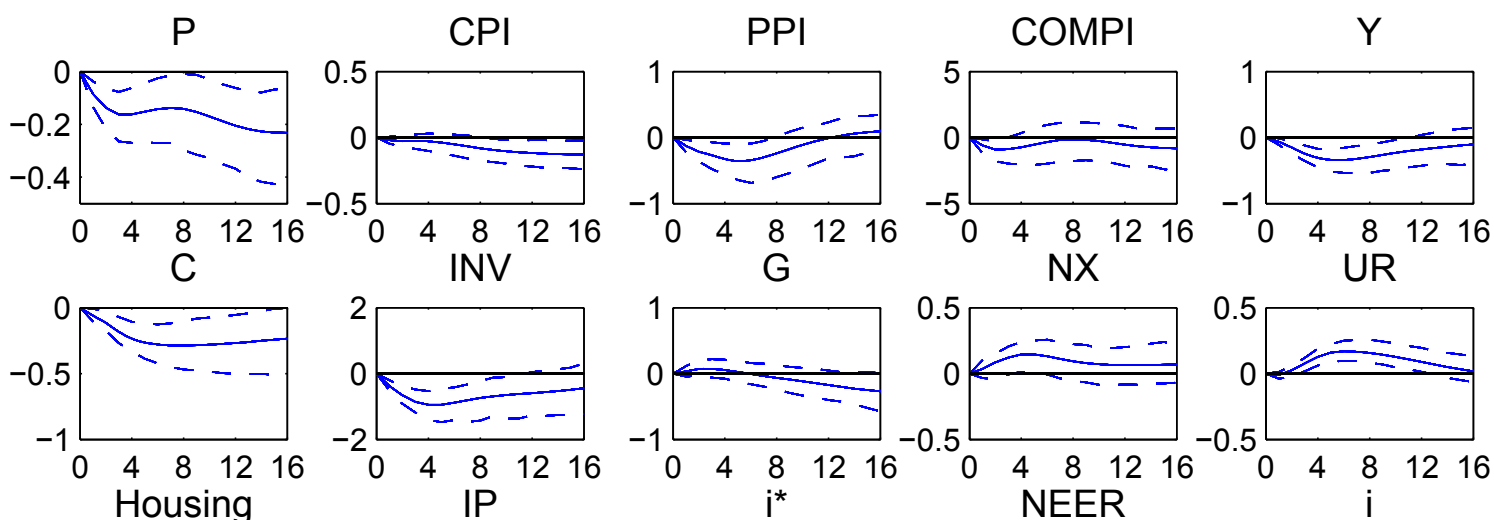

UR
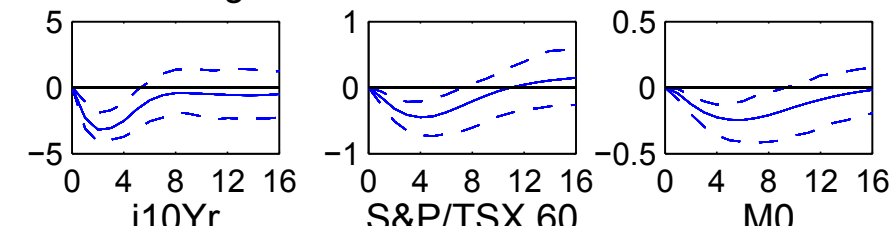

NEER
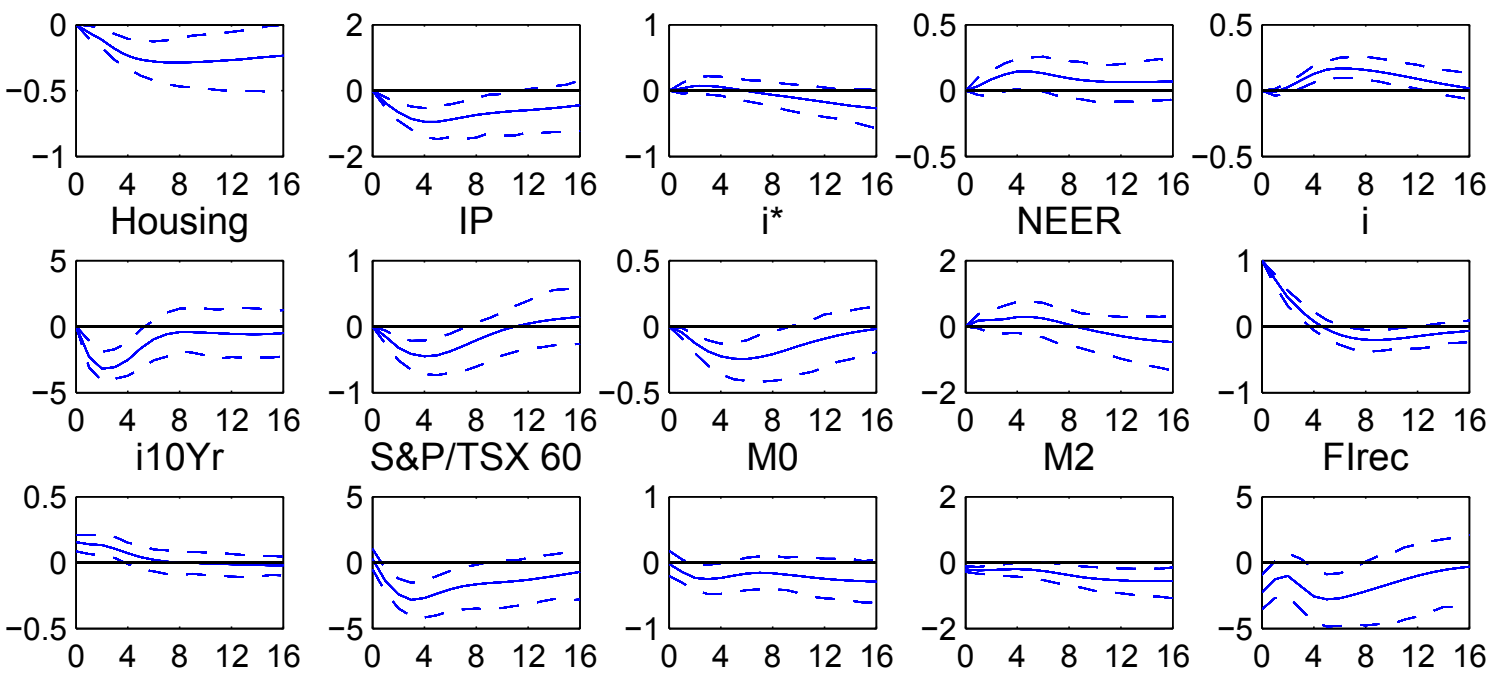

FIrec

Flpay

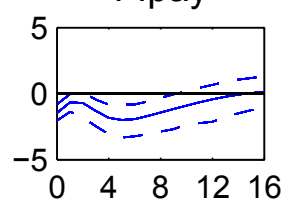

Figure E6: Canada - Specification with total gross foreign investment income flows

Notes: The figure reports impulse response functions to a 100 basis points monetary policy shock in percentage points at the median (solid line) and the 16 th and 84 th percentiles (dashed lines) of the distribution. In contrast to the baseline estimations above, the nominal effective exchange 

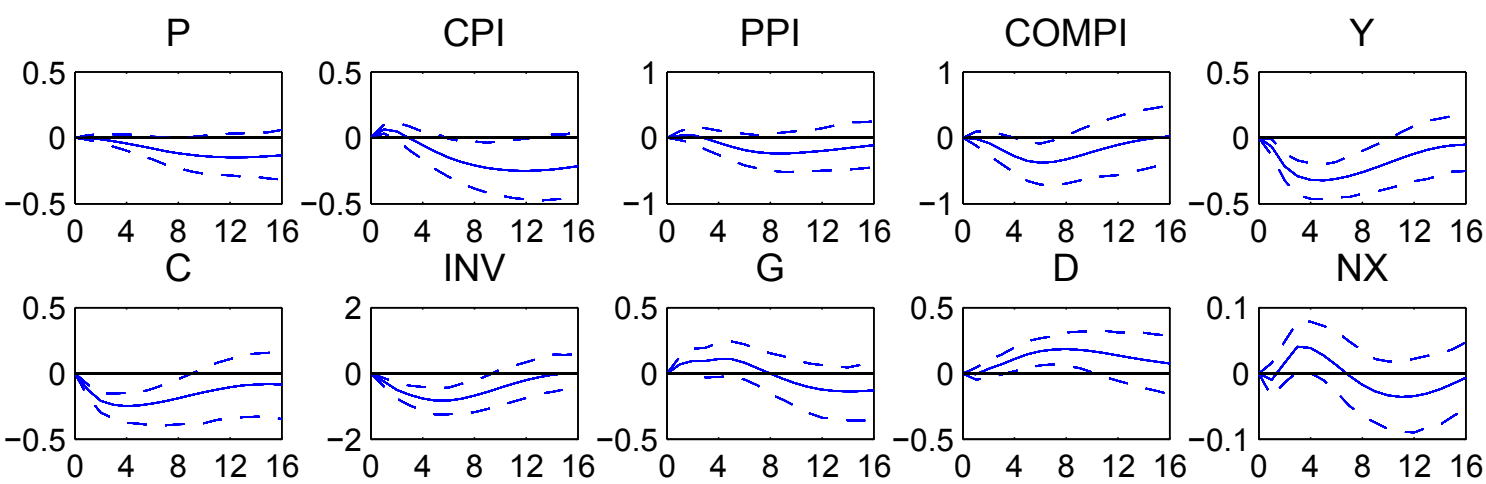

NX

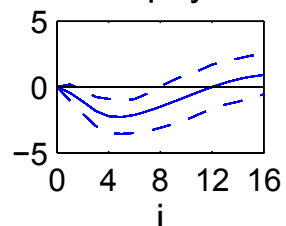

Flrec
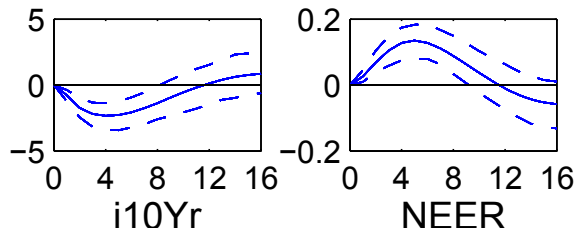

NEER

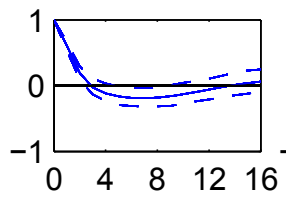

TR
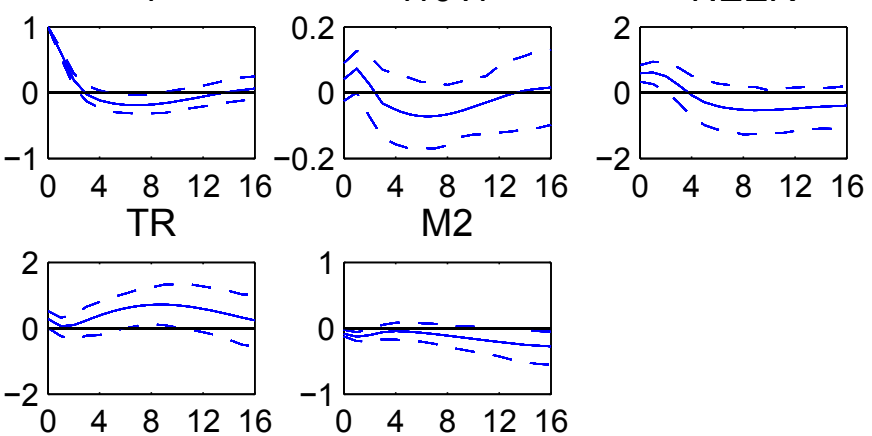

$\mathrm{M} 2$

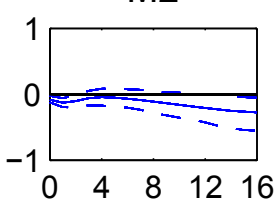

Housing
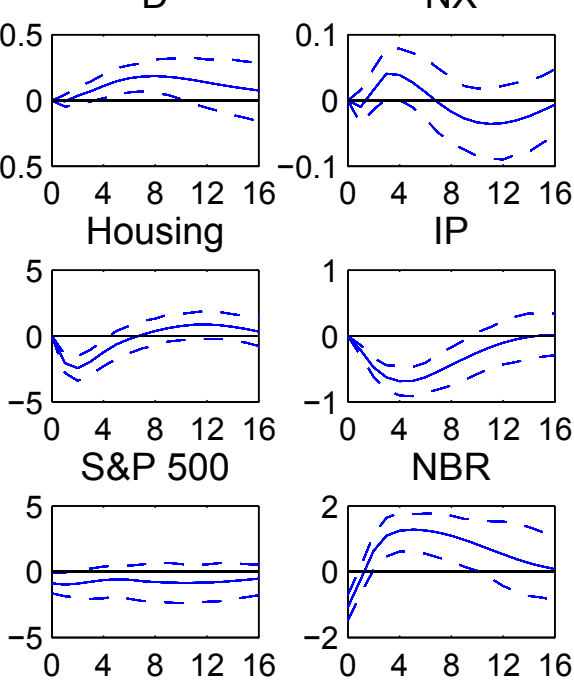

Figure E7: United States - Specification with total gross foreign investment income flows

Notes: The figure reports impulse response functions to a positive 100 basis points monetary policy shock in percentage points at the median (solid line) and the 16 th and 84 th percentiles (dashed lines) of the distribution. In contrast to the baseline estimations above, foreign investment 

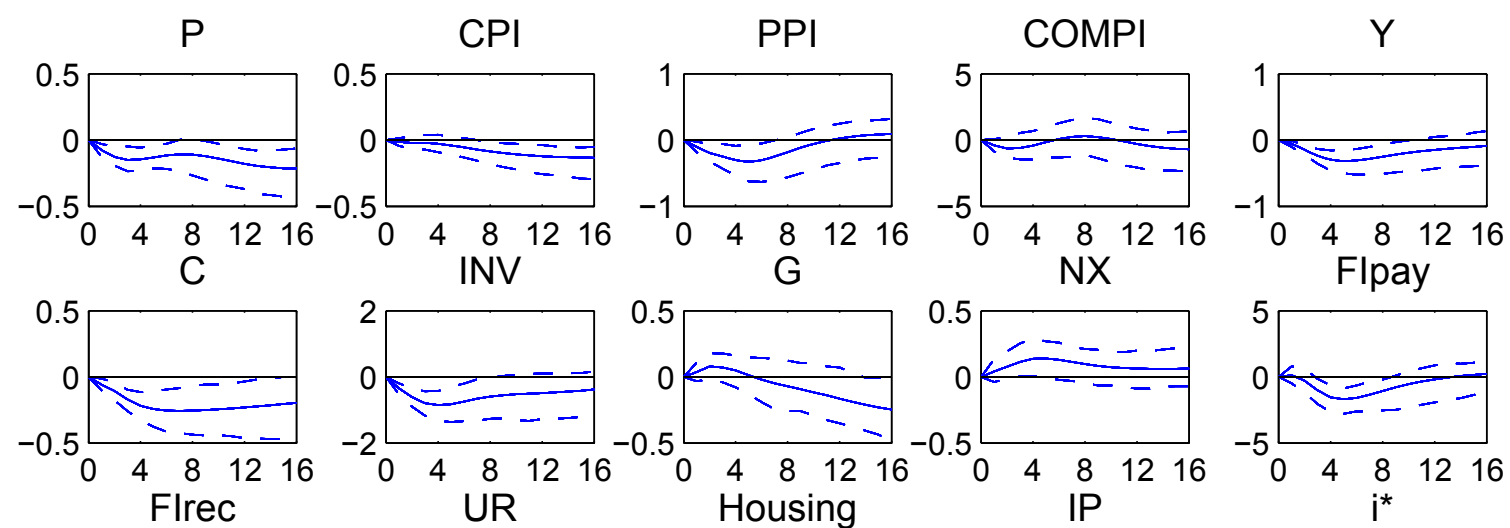

Flpay
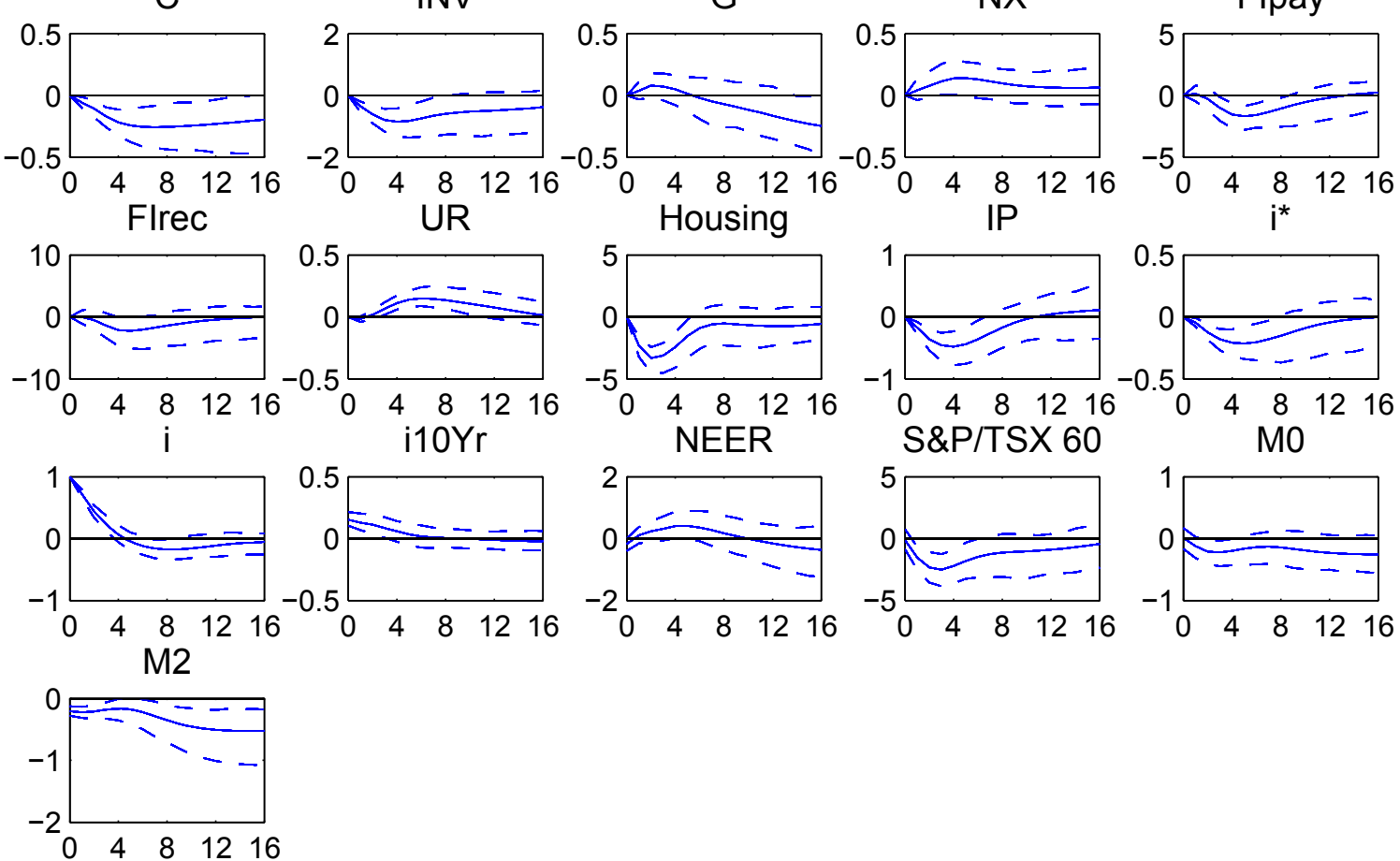

Figure E8: Canada - Specification with total gross foreign investment income flows 


\section{Recent SNB Working Papers}

2014-2 Simone Auer: Monetary Policy Shocks and Foreign Investment Income: Evidence from a large Bayesian VAR

2014-1 Thomas Nitschka: The Good? The Bad? The Ugly? Which news drive (co)variation in Swiss and US bond and stock excess returns?

2013-11 Linda S. Goldberg and Christian Grisse: Time variation in asset price responses to macro announcements.

2013-10 Robert Oleschak and Thomas Nellen: Does SIC need a heart pacemaker?

2013-9 Gregor Bäurle and Elizabeth Steiner: How do individual sectors respond to macroeconomic shocks? A structural dynamic factor approach applied to Swiss data.

2013-8 Nikolay Markov and Thomas Nitschka: Estimating Taylor Rules for Switzerland: Evidence from 2000 to 2012.

2013-7 Victoria Galsband and Thomas Nitschka: Currency excess returns and global downside market risk.

2013-6 Elisabeth Beusch, Barbara Döbeli, Andreas Fischer and Pınar Yeşin: Merchanting and Current Account Balances

2013-5 Matthias Gubler and Matthias S. Hertweck: Commodity Price Shocks and the Business Cycle: Structural Evidence for the U.S.

2013-4 Christian Grisse and Thomas Nitschka: On financial risk and the safe haven characteristics of Swiss franc exchange rates.
2013-3 Simone Meier: Financial Globalization and Monetary Transmission.

2013-2 Nicole Aregger, Martin Brown and Enzo Rossi: Transaction Taxes, Capital Gains Taxes and House Prices.

2013-1 Andreas Kettemann and Signe Krogstrup: Portfolio balance effects of the SNB's bond purchase program.

2012-16 Katja Drechsel and Rolf Scheufele: Bottom-up or Direct? Forecasting German GDP in a Data-rich Environment.

2012-15 Raphael A. Auer: What Drives Target2 Balances? Evidence From a Panel Analysis.

2012-14 Raphael A. Auer and Raphael S. Schoenle: Market Structure and Exchange Rate Pass-Through.

2012-13 Andreas Kropf and Philip Sauré: Fixed Costs per Shipment.

2012-12 Sébastien Kraenzlin and Thomas Nellen: Access policy and money market segmentation.

2012-11 Raphael A. Auer, Thomas Chaney and Philip Sauré: Quality Pricing-to-Market.

2012-10 Thomas Nitschka: Global and country-specific business cycle risk in time-varying excess returns on asset markets.
From 2014, this publication series will be renamed SNB Working Papers.

All SNB Working Papers are available for download at: www.snb.ch, Research

Subscriptions or individual issues can be ordered at: Swiss National Bank

Library

P.O. Box

$\mathrm{CH}-8022$ Zurich

Phone: +41446313284

Fax: +41446318114

E-mail: library@snb.ch 
